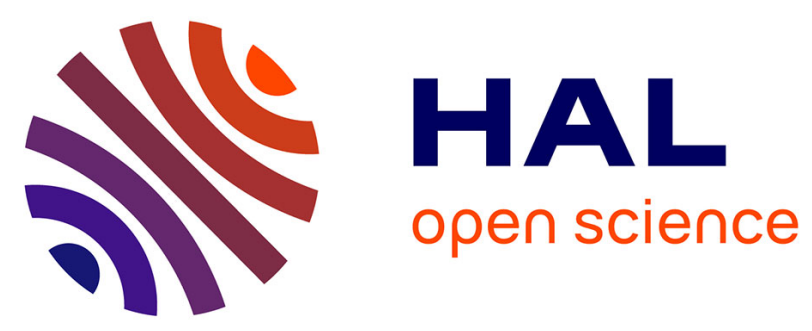

\title{
Stump closure reinforcement with absorbable fibrin collagen sealant sponge (TachoSil@) does not prevent pancreatic fistula after distal pancreatectomy: the FIABLE* multicenter controlled randomized study
}

Antonio Sa Cunha, Nicolas Carrere, B. Meunier, Jean-Michel Fabre, Alain Sauvanet, Patrick Pessaux, Pablo Ortega-Deballon, Abe Fingerhut, François Lacaine

\section{- To cite this version:}

Antonio Sa Cunha, Nicolas Carrere, B. Meunier, Jean-Michel Fabre, Alain Sauvanet, et al.. Stump closure reinforcement with absorbable fibrin collagen sealant sponge (TachoSil®) does not prevent pancreatic fistula after distal pancreatectomy: the FIABLE* multicenter controlled randomized study. American Journal of Surgery, 2015, 210 (4), pp.739-748. 10.1016/j.amjsurg.2015.04.015 hal-01163242

HAL Id: hal-01163242

https://hal-univ-rennes1.archives-ouvertes.fr/hal-01163242

Submitted on 24 Nov 2015

HAL is a multi-disciplinary open access archive for the deposit and dissemination of scientific research documents, whether they are published or not. The documents may come from teaching and research institutions in France or abroad, or from public or private research centers.
L'archive ouverte pluridisciplinaire HAL, est destinée au dépôt et à la diffusion de documents scientifiques de niveau recherche, publiés ou non, émanant des établissements d'enseignement et de recherche français ou étrangers, des laboratoires publics ou privés. 
Background: evaluate the effectiveness of TachoSilß sponge on distal pancreatectomy remnant stump in reducing the rate and severity of post-operative pancreatic fistula (POPF)

Methods:

All consecutive patients requiring distal pancreatectomy were randomized in 45 centers. Principal endpoint: onset of "clinically relevant" POPF. Univariate and multivariate analyses searched for predictive factors.

\section{Results}

Of 270 patients randomized in 45 centers (134 with TachoSil@; 136 without), 150/270(55.6\%) sustained a POPF (74 clinically relevant; 76 clinically silent $(27.4 \%$ and $28.1 \%$, respectively): no statistically significant difference (NS) was found between patients with (41(30.6\%) vs. 33(24.3\%) without TachoSil $(p=0.276)$, or overall POPF (73(54.5\%) with vs. $77(56.6 \%)$ without TachoSil $(p=0.807)$, but more clinically relevant POPF after hand-sewn (32.3\%) vs. mechanical closure $(19.8 \%)(p=0.025)$ and, in case of splenic preservation, after splenic vessel ligation $(15 / 32,46.9 \%)$ vs. vascular preservation $(17 / 72,23.6 \%)(p=0.024)$. Hand-sewn pancreatic remnant closure $(p=0.023)$ and splenic vessel ligation in splenic preservation $(p=0.035)$ were independent predictive factors for the onset of clinically relevant POPF. 
Conclusion: TachoSil@ sponge reinforcement of the proximal remnant after distal pancreatectomy reduced neither the rate nor the severity of POPF. 
Stump closure reinforcement with absorbable fibrin collagen

sealant sponge (TachoSil®) does not prevent pancreatic

fistula after distal pancreatectomy: the FIABLE* multicenter controlled randomized study

Antonio Sa Cunha ${ }^{1}, \mathrm{MD}, \mathrm{PhD}$, Nicolas Carrere ${ }^{2}, \mathrm{MD}, \mathrm{PhD}$, Bernard Meunier $^{3}, \mathrm{MD}, \mathrm{PhD}$, Jean-Michel Fabre ${ }^{4}, \mathrm{MD}$, Alain Sauvanet ${ }^{5}$, MD, Patrick Pessaux ${ }^{6}, \mathrm{MD}, \mathrm{PhD}$, Pablo Ortega-Deballon ${ }^{7}, \mathrm{MD}$, PhD, Abe Fingerhut ${ }^{8}, \mathrm{MD}$, François Lacaine ${ }^{9}, \mathrm{MD}, \mathrm{PhD}$, and the French Fédération de Recherche EN Chirurgie (FRENCH)

${ }^{1}$ Centre hépato-biliaire, Hôpital Paul Brousse (Villejuif), ${ }^{2}$ Service de chirurgie générale et digestive, Hôpital Purpan (Toulouse),

${ }^{3}$ Service de Chirurgie hépato-biliaire et digestive, Hôpital Pontchaillou (Rennes)

${ }^{4}$ Service de chirurgie digestive A, Hôpital St Eloi (Montpellier)

${ }^{5}$ Service de chirurgie hépato-bilio-pancréatique, Hôpital Beaujon (Clichy)

${ }^{6}$ Service de chirurgie hépato-bilio-pancréatique, Hôpital Hautepierre (Strasbourg)

${ }^{7}$ Service de chirurgie digestive et cancérologique, Hôpital du Bocage (Dijon)

${ }^{8}$ Section for Surgical Research, Department of Surgery, Medical University of Graz, Austria

${ }^{9}$ Service de chirurgie digestive et viscérale, Hôpital Tenon (Paris) *FIABLE : Efficacité sur la survenue des FIstules pAncréatiques et la tolérance de l'éponge de TachoSilß appliquée sur la tranche de 
section pancréatique chez les patients ayant suBi une pancréatectomie distaLE pour tumeur.

This study was approved by the Committee for the Protection of Patients under the number CPP 08012, and registered with the European Clinical Trials Database EUDRACT under the number 2008-001253-17.

Financial disclosure: Nycomed supported the performance of this study.

\section{Running title :}

\section{Pancreatic stump fistula prevention}

\section{Emails:}

antonio.sacunha@pbr.aphp.fr,

carrere.n@chu-toulouse.fr,

bernard.meunier@chu-rennes.fr, im-fabre@chu-montpellier.fr, alain.sauvanet@bjn.aphp.fr, patrick.pessaux@chru-strasbourg.fr, pablo.ortega-deballon@chu-dijon.fr, abefingerhut@aol.com, francois.lacaine@tnn.aphp.fr 


\section{Introduction}

While distal pancreatic resections are performed less frequently than other pancreatectomies (1), the rate of post-operative pancreatic fistula (POPF) is high, ranging from $5 \%$ (2) to $64 \%(3-5)$, according to the definition used (4).

Several procedures have been proposed to reduce the rate and/or severity of POPF after distal pancreatectomy (3): decreasing digestive tract secretions (6), main duct ligation (7), various techniques of division and/or stump closure (1,5,8-10), different types and durations of abdominal drainage $(11,12)$, and stump reinforcement with omentum, absorbable or non-absorbable mesh or biological glue $(8,13-18)$. While some reinforcement materials have a mechanical action, reducing the traction on the sutured edges, others act by enhanced healing (14). TachoSil $囚$, a sponge composed of horse collagen, impregnated with human thrombin and fibrinogen, stabilized by albumin, combines enhanced healing while exercising a hemostatic role (19) and has been used to improve hemostasis and bilistasis on the surface of the divided liver (18).

Several uncontrolled studies seem to indicate that absorbable mesh reinforcement could reduce the POPF rate after distal pancreatectomy $(13,14)$. One randomized study has shown that Seamguard $®$ or Peristrips Dry $®$ reinforcement of stapled stump closure was effective in decreasing the fistula rate (17). However, 
to date, only one controlled trial has studied the role of TachoSil® for stump closure in distal pancreatectomy (19), concluding that TachoSil $囚$ did not reduce the overall POPF rate.

The goal of the present study was to report the results of a French multicenter randomized controlled study evaluating the role of the TachoSil $\circledast$ sponge in reducing the rate and the severity of pancreatic POPF after distal pancreatectomy, separating clinically silent from clinically relevant POPF.

\section{Methods}

\section{Patients}

Patients requiring complete removal of the distal pancreas for benign or malignant tumors of the pancreatic body or tail were eligible for this randomized controlled trial. Inclusion criteria required: life expectancy of at least six months, written informed consent before randomization, no history of allergy to human thrombin and fibrinogen or collagen, no preoperative signs of chronic pancreatitis, and absence of indications for simple enucleation or intra-abdominal anastomosis, including pancreatoenterostomy (to eliminate fistula related to the breakdown of these anastomoses (19)). Patients were randomized to receive the sponge, or not, only after the distal pancreas had been removed, the stump was closed and the surgeon was sure that the TachoSil $\circledast$ sponge could be applied under satisfactory conditions.

\section{Intervention}


Surgery could be performed either via laparotomy or laparoscopy, with or without splenectomy, and in case of splenic preservation, with ligature (but preserving the short gastric vessels, as described by Warshaw (20)) or not of the splenic vessels. The pancreatic stump had to be closed, either manually or stapled, as per surgeon's choice. Selective main pancreatic duct closure (suture) was not mandatory but was recommended whenever feasible. The TachoSil@ sponge was placed on the stump without sutures, overlapping the closure line by at least $2.5 \mathrm{~cm}$ and held there for at least 3 minutes to ensure that it stuck to the stump. Additional techniques such as abdominal drainage, omentoplasty and/or application of biological glue were left to the appreciation of the surgeon.

\section{Definition of post-operative pancreatic fistula (POPF)}

POPF was defined according to the International Study Group on Pancreatic Fistula (ISGPF) (21) as any measurable amount of drainage fluid, with amylase concentration greater than 3 times the upper limit of normal in the serum on or after post-operative day 3 , irrespective of its color or aspect, exteriorized through a drain or retrieved during reoperation or via percutaneous (sonography or CT-guided) aspiration.

\section{Definition of severity}

This study was double blinded: neither the patients nor the independent committee whose role was to evaluate the severity of 
POPF were aware of the allocations. Patients were categorized into two groups of POPF $(17,21,22)$ : one without any clinical signs suggestive of any postoperative complication including patients without any signs of POPF and patients with grade A severity (with no clinical impact (mainly no prolonged hospital stay)), categorized as being "clinically silent", the other "clinically relevant" (with impact on the patient's hospital course), including Grades B and C severity.

\section{Judgment criteria}

The primary endpoint was the onset of "clinically relevant" POPF. The secondary endpoints were: a) the overall POPF rate (ISGPF Grades $A+B+C), b$ ) interval between operation and the onset of POPF, c) median duration of post-operative stay in intensive care and/or resuscitative care units and overall hospital stay, d) number of post-operative complication(s) (other than POPF), e) adverse event(s) i.e. any potentially harmful manifestation related or not to the product under investigation, and f) mortality.

\section{Follow-up}

All patients underwent routine physical examination: daily during hospitalization and at three months ( \pm 15 days) after operation, date at which the diagnosis of POPF and mortality were definitively determined. 


\section{Adverse events related to TachoSiIß}

All adverse events were reported immediately, examined and categorized by an independent data safety monitoring board (DSMB): the causality (not related, possibly related or probably related) was evaluated (23).

\section{Statistical methods}

Randomization was centralized by a vocal server and stratified according to the approach (laparotomy or laparoscopy). The $\alpha$ and $\beta$ risks were fixed at 0.05 and 0.10 , respectively, providing $90 \%$ power (one-sided test). Based on an expected decrease in the POPF rate from $30 \%$ to $15 \%$, the number of patients necessary to satisfy these hypotheses was 262 patients (131 in each group). No intermediary analysis was planned. The predictive factors for the onset of "clinically relevant" POPF were analyzed by univariate and multivariate (step-wise regression) analyses. The log rank test was used to compare variables related to durations.

\section{Results}

Two hundred and ninety-seven patients underwent randomization in 45 centers between March 5, 2009 and March 10, 2011. As seen in the CONSORT flow chart (24), of these 297 patients, 27 were ultimately found to not correctly fulfill the entry requirements, and were not included in final analysis (figure 1). 
Of the 270 patients retained for analysis, 134 were allotted to

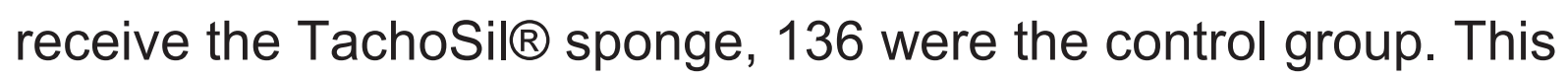
was the intention-to-treat (ITT) population.

Two patients allotted to TachoSil ${ }^{\circ}$ did not receive the sponge while three patients initially allotted to the control group, actually had the TachoSil $\circledast$ sponge, without any diagnostic or operative reason to back this choice. Therefore, as concerns the analysis as treated (per protocol group), exactly half (135) of the 270 randomized patients were assigned to each group. As the discrepancy between the two populations represents only $1.9 \%$ of the entire population, and according to the CONSORT recommendations (24), only the ITT analysis (134 vs. 136) is reported hereafter.

No statistically significant differences were found in patient demographics (gender, age or body mass index) (table 1).

The final pathology reports of the resected specimen showed that $128 / 270$ patients $(47.4 \%)$ had benign disease while $142(52.6 \%)$ had malignant disease $(p=0.223)$. Most cancers were pancreatic adenocarcinoma (26.7\% of the whole population) (table 2 ).

No statistically significant differences were noted between the two groups as concerns the duration of operation, the number of patients admitted to and duration of patient stay in intensive care and/or resuscitation units or overall duration of hospital stay (Table 3 ), parenchymal consistency of the pancreatic remnant or the technical aspects of the operation (selective closure of the main 
pancreatic duct, type of division and/or stump closure, laparoscopy or laparotomy, abdominal drainage or not, splenic preservation or not and, in case of preservation, ligation or not of the main splenic vessels (Table 4).

\section{POPF}

Of the 270 patients, 150 (55.6\%) sustained a POPF (ISGPF Grades A, B and C) of which 74 (49.3\%) were clinically relevant while $76(50.7 \%)$ were clinically silent $(27.4 \%$ and $28.1 \%$, respectively, of the total number of patients) (table 5).

\section{Comparison of patients with or without TachoSil@}

Clinically relevant POPF

Forty-one patients (30.6\%) had a clinically relevant POPF in the TachoSil@ group vs. $33(24.3 \%)$ in the control group $(p=0.276)$ (Table 5). The odds ratio (OR) was 1.376 with a 95\% confidence interval $(95 \% \mathrm{Cl})$ equal to [0.877-2.160]). The hypothesis that clinically relevant POPF occurred less often when TachoSil@ was used, cannot be retained.

POPF (ISGPF Grades A, B and C)

No statistically significant difference was noted between patients with overall POPF in either group: 73 (54.5\%) in the TachoSil® group vs. $77(56.6 \%)$ in controls $(p=0.807)$ (Table 5). The OR was 0.917, (95\% Cl: [0.613-1.372]). The hypothesis that any grade of POPF occurred less often after use of TachoSil® cannot be retained. 
There was no statistically significant difference found between the two groups as concerns the interval between operation and the onset of clinical POPF (logrank test: $p=0.957$ ) or in the 10 patients undergoing surgical operation or drainage of an intra-abdominal collection after hospitalization: 7 vs. 3 , respectively $(p=0.217)$.

\section{Prognostic factors of POPF}

In univariate analysis, no statistically significant difference was found according to whether the POPF occurred in patients with benign $(34 / 128)$ or malignant $(40 / 142)$ disease $(p=0.786)$.

The duration of operation was not statistically different in patients with or without clinically relevant POPF. Conversely, the duration of stay in intensive care and resuscitative care was longer $(p=0.003$ and $p<0.001$, respectively) for patients who sustained a clinically relevant POPF.

No statistically significant differences were noted in the rate of clinically relevant POPF according to whether or not: a) the pancreatic remnant consistency was normal (vs. chronic pancreatitis) $(p=0.790) ; b)$ the main duct was sutured $(p=0.130), c)$ drainage was performed $(p=1.0)$, and in subgroup analysis, whether patients underwent splenic preservation or splenopancreatectomy $(p=0.331)$. Conversely, there were statistically significantly more clinically relevant POPF when pancreatic remnant closure was hand-sewn (32.3\%) vs. mechanical closure $(19.8 \%)(p=0.025)$ and, in case of splenic 
preservation, twice as many clinically relevant POPF when the splenic vessels were ligated $(15 / 32,46.9 \%)$ vs. vessel preservation $(17 / 72,23.6 \%)(p=0.024)($ table 6$)$.

Of the 270 patients, 199 (74.7\%) underwent laparotomy while 71 (26.3\%) had a laparoscopic approach. No statistically significant difference was noted in the clinically relevant POPF rate between laparotomy vs. laparoscopy (30.2\% (60/199) vs. 19.7\% (14/71): $(p=0.121)$. Spleen preservation was performed in 104 patients (38.5\%), more often via laparoscopy (44/71: 62.0\%) than via laparotomy (60/199: 30.2\%), $(p=0.001)$. When the spleen was preserved, 32 patients underwent the Warshaw technique (30.8\%), 11 via laparoscopy vs. 21 via laparotomy, $(p=0.322)$, with no statistically significant difference in the clinically relevant POPF rate according to route (4/11 via laparoscopy vs. 11/21 via laparotomy $(p=0.470)$.

The variables entered into the multivariate analysis $(p<0.10$ in univariate analysis) included age, method of pancreatic remnant closure, splenic preservation (with or without splenic vessel ligation), performance of additional procedures or not: only handsewn closure of the pancreatic remnant $(p=0.023)$ and the ligation of the splenic vessels after splenic preservation $(p=0.035)$ were found to be independent predictive factors for the onset of clinical POPF.

\section{Safety}


According to the DSMB, 756 adverse events were considered to be "not related", while 85 were considered as "possibly related" to the use of TachoSil $\circledR$. However, none of these adverse events were reported to be related to the onset of any post-operative complication.

\section{Morbidity}

Overall, there were 45 post-operative complications (table 7).

Nevertheless, there was no statistically significant difference found between patients with or without TachoSil® or in patients sustaining POPF or not.

\section{Mortality}

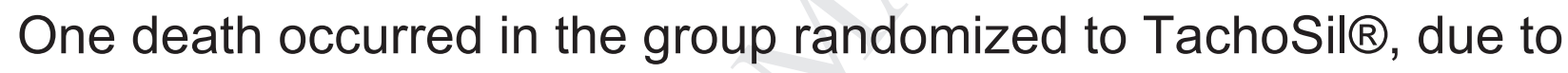
acute respiratory distress, while two deaths occurred in the group without TachoSil $囚$, one related to shock associated with peritonitis and the other due to respiratory failure secondary to pulmonary embolism in a patient with infection and unexpected rapidly generalized cancer.

\section{Discussion}

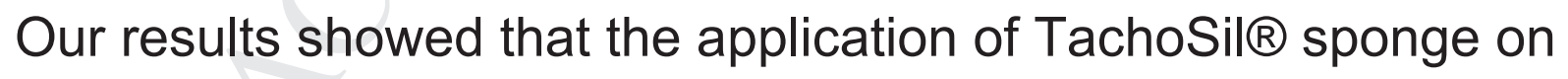
the proximal remnant after distal pancreatectomy reduced neither the rate nor the severity of POPF.

This is the second negative study on the use of TachoSil@ in this indication (19). As highlighted recently $(25,26)$, it is timely and highly relevant to publish well-conducted negative studies in order 
to avoid publication and reporting bias, more and more prevalent today, and a real threat to the validity of decision-making for the care of our patients.

While the primary endpoint and the results were close to those in the only previous randomized study on the same topic with the same product (19), our study differed in that: a) we showed that

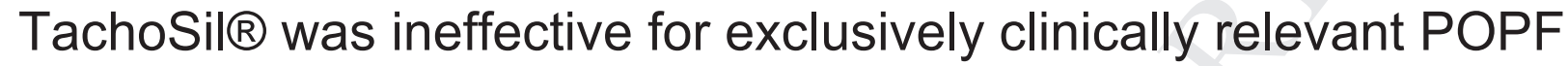
as well as for all grades of POPF, b) the evaluation of patient outcome for both the diagnosis of POPF and the causality of adverse events was double blinded, c) the power of making a false negative conclusion was twice as strong (our beta error $(10 \%)$ was half that of the Italian study $(20 \%))$. Of note, as others $(17,22)$, our trial clearly distinguishes itself from the Italian study (19) in that we separated the clinically relevant from the clinically silent grade A POPF. Otherwise, the overall POPF (including Grade $A+B+C$ ) would have been $55.6 \%$, still slightly less than the $65 \%$ reported in the Italian study (19).

In multivariable analysis, we found that hand-sewn closure of the pancreatic stump and ligation of the splenic vessels in case of splenic preservation were statistically significantly associated with an increased risk for clinically relevant POPF. This is of interest in the modern era where more and more distal pancreatectomies are being performed laparoscopically $(5,17)$ : stapled stump closure and splenic vessel preservation are the preferred methods in laparoscopic distal pancreatectomy. 
At least 18 observational (9), two randomized controlled trials $(8,9)$ and one meta-analysis (3) have compared hand-sewn to some other pancreatic stump closure procedure.

Both the systematic review of observational studies (9) and the meta-analysis of Knaebel et al. (3) were in favor of stapled closure. This is in agreement with our findings but contrasts with those of two high-volume institutional studies $(1,5)$ that found that stapled stump closure was associated with a higher POPF rate, perhaps because of the crushing injury to the pancreatic parenchyma by the jaws of the linear stapler, and one other high-volume study (10) that did not find any difference. Likewise, the randomized studies of Bassi et al. (8) and Diener et al. (9) both showed a non-statistically significant difference in the POPF rate in favor of hand sewn stump closure. Of note, in all of these studies $(1,3,8,9)$, the authors did not distinguish between clinically silent and clinically relevant POPF, as we did in our study.

Neither splenic preservation nor splenectomy influenced the POPF rate in our study. Splenic preservation was found to be a significant predictive factor for POPF in two studies $(19,27)$, but no distinction was made according to whether the splenic vessels were preserved or not. Conversely, Kleef et al. (1) found a just significant higher rate $(11.2 \%$ vs. $5.1 \%(p=0.048))$ of POPF when splenectomy was performed.

Conversely, our higher rate of POPF after the Warshaw technique (20) is in accordance with Adam et al. (28). 
This contrasts with one case-controlled study (29) and the Massachusetts General Hospital series (30), which found that the POPF rate did not differ statistically significantly whether splenectomy or the Warshaw technique (20) were performed. This is also in line with Jain et al., who in a recent systematic review (31) was unable to show any statistically significant difference in the POPF rate between the Warshaw technique and preservation of the splenic vessels $(p=0.15)$. Here again, however, two of the studies $(29,30)$ did not use the same definition of pancreatic fistula and, in three studies (29-31), no distinction was made as to the severity (21). One possible reason behind our findings could be that distinguishing between clinically relevant and clinically silent POPF unmasks the potential ischemic effects of splenic vessel ligation.

Our overall POPF rate was 55\%, slightly lower that the Italian randomized trial $(65 \%)(19)$, but considerably higher than that reported by Diener et al. in the DISPACT trial (9). However, we searched for this complication over a three-month period, compared to the $7(30 \%)$ and 30 day (36\%) analyses in the DISPACT trial. Moreover, $15 \%$ of their patients had chronic pancreatitis or pseudo-cysts, considered to be at low-risk for development of POPF.

One systematic review and meta-analysis (32) found that laparoscopic distal pancreatectomy had a statistically significant protective effect on the rate of POPF. This contrasts with the 
results of our study as well as those of Cho et al. (33) who found that post-operative complications (including POPF) did not differ between laparoscopy and laparotomy. Of note, the meta-analysis (32) involved only observational studies and series were quite heterogeneous, while the Central Pancreas Consortium study (33) involved only expert centers, a potential selection bias.

Laparoscopy was performed in 71 of 270 patients in our study (26\%), slightly more than the $20 \%$ in the Italian study (19). Splenic preservation techniques may be easier to perform laparoscopically: almost two thirds of splenic preservation operations $(62.0 \%)$ were performed via laparoscopy in our study, higher than the $48 \%$ rate reported by Montorsi et al. (19). Our rate of splenic preservation was higher among procedures performed by laparoscopy than by an open approach (48\% vs. $14 \%, \mathrm{P}<0.001)$, possibly in relation to the $47.4 \%$ proportion of benign disease in our study, and facilitating the temptation not to perform splenectomy and to spare splenic vessels with the minimally invasive approach (34). Conversely, it is possible that mandatory preservation of the short gastric vessels in the Warshaw technique (20) might be more difficult to perform laparoscopically explaining why $11 / 32=34.5 \%$ were performed via laparoscopy vs. $21 / 32=66 \%$ via laparotomy in our study.

In contrast to the results in our trial, several studies found that elective closure of the main pancreatic duct had a protective effect $(7,35)$. However, our study was not powered to determine the role of elective main pancreatic duct closure (secondary end-point in 
our study) on prevention of POPF and to the best of our knowledge, there are no randomized controlled trials on this technical detail in the literature, only multivariate analyses $(7,35)$. Possible reasons for the discrepancy of results might be the variation in technical aspects of duct closure from one institution to another, and/or the small number of patients in the studies.

In spite of the outcomes of two randomized controlled studies $(11,12)$, the debate as to the need of post-operative drainage (preventive effect on occurrence of clinical POPF or detection of POPF vs. its potential deleterious effects) has never been closed. Most surgeons in our series (95.6\%) left a drain. In our study, there was no difference in the rate or severity of POPF whether patients had a drain or not.

Our study confirms that the use of TachoSil is safe, as it was not associated with any adverse events. This is in accordance with the Italian study (19) as well as a non-interventional multicenter prospective, surveillance study (36) in a total of 3098 patients recruited at 227 centers in 12 European countries.

There are several possible weaknesses in our study. First, 45 centers participated in this multicenter study, possibly explaining the relatively high overall fistula rate and the wide range of techniques used. However, this is representative of real life surgery. Second, our low proportion of malignant disease (53.\%) in relation to the literature $(1,3,19)$ potentially represents a selection bias, but this also reflects the multicenter character of our study, 
and the fact that general hospitals as well as specialized pancreatic surgery centers participated in our study.

\section{Conclusion}

While the concept of reinforcing the stump closure with a resorbable collagen sponge after distal pancreatectomy appeared interesting, our results confirm those from the only other previous controlled trial on this topic: the inability of this adjunctive method to reduce the rate of POPF, whether overall or, as shown in our study only, the rate of clinically relevant POPF. However, it is well known that several studies, especially when the results are negative, are necessary before strong and methodologically sound conclusions can be drawn as to the usefulness or futility of therapeutic decisions $(37,38)$. As one controlled randomized trial (17) has shown a positive effect of non-absorbable mesh reinforcement on the pancreatic stump after distal pancreatectomy, further studies are needed with different types of material used for reinforcement. 


\section{References}

1) Kleeff J, Diener MK, Z'graggen K, Hinz U, Wagner M, Bachmann J, et al. Distal pancreatectomy: risk factors for surgical failure in 302 consecutive cases. Ann Surg 2007; 245: 573-582

2) Lillemoe KD, Kaushal S, Cameron JL Sohn TA, Pitt HA, Yeo CJ. Distal pancreatectomy indications and outcome in 235 patients. Ann Surg 1999; 229: 693-700

3) Knaebel HP, Diener MK, Wente MN, Büchler MW, Seiler CM. Systematic review and meta-analysis of technique for closure of the pancreatic remnant after distal pancreatectomy. Br J Surg 2005; 92: 539-546

4) Hackert T, Werner J, Buchler MW. Postoperative pancreatic fistula. Surgeon 2011; 9: 211-7

5) Reeh M, Nentwich MF, Bogoevski D, Koenig AM, Gebauer F, Tachezy M, et al. High surgical morbidity following distal pancreatectomy: still an unsolved problem World J Surg 2011; 35: 1110-7

6) Gurusamy KS, Koti R, Fusai G, Davidson BR. Somatostatin analogues for pancreatic surgery (Review). Cochrane Library 2012

7) Bilimoria MM, Cormier JN, Mun Y, Lee JE, Evans DB, Pisters PW. Pancreatic leak after left pancreatectomy is reduced following main pancreatic duct ligation. Br J Surg 2003; 90: 190-196 
8) Bassi C, Butturini G, Falconi M, Salvia R, Sartori N, Caldiron E. Prospective randomized pilot study of management of the pancreatic stump following distal resection. HPB 1999; 1 : 203-207

9) Diener MK, Seiler CM, Rossion I, Kleeff J, Glanemann M, Butturini $G$ et al. Efficacy of stapler versus hand-sewn closure after distal pancreatectomy (DISPACT): a randomised, controlled multicentre trial. The Lancet, 2011; 377: 1514-1522

10) Ferrone CR, Warshaw AL, Rattner DW, Berger $D$, Zheng $\mathrm{H}$, Rawal B, et al. Pancreatic fistula rates after 462 distal pancreatectomies: staplers do not decrease fistula rates. $J$ Gastrointest Surg. 2008;12:1691-1698

11) Conlon $K C$, Labow $D$, Leung $D$, Smith $A$, Jarnagin $W$, Coit DG, et al. Prospective Randomized Clinical Trial of the Value of Intraperitoneal Drainage After Pancreatic Resection Ann Surg 2001; 234: 487-94

12) Bassi C, Molinari E, Malleo G, Crippa S, Butturini G, Salvia R, et al. Early Versus Late Drain Removal After Standard Pancreatic Resections Results of a Prospective Randomized Trial. Ann Surg 2010; 252: 207-14

13) Mc Johnston F, Cavataio A, Strasberg SM, Hamilton NA, Simon PO Jr, Trinkaus K, et al. The effect of mesh reinforcement of a stapled transection line on the rate of pancreatic occlusion failure after distal pancreatectomy: 
review of a single institution's experience. HPB (Oxford) 2009: 11: 25-31

14) Thaker RI, Matthews BD, Linehan DC, Strasberg SM, Eagon JC, Hawkins WG. Absorbable mesh reinforcement of a stapled pancreatic transection line reduces the leak rate with distal pancreatectomy J Gastrointest Surg 2007; 11: 5965

15) Ohwada S, Ogawa T, Tanahashi T, Nakamura S, Takeyoshi I, Ohya I, et al. Fibrin glue sandwich prevents fistula following distal pancreatectomy World J Surg 1998; 22: 494-8

16) Velanovich $V$ The use of tissue sealant to prevent fistula formation after laparoscopic distal pancreatectomy Surg Endosc 2007; 21: 1222 (one page)

17) Hamilton NA, Porembka MR, Johnston FM, Gao F, Strasberg SM, Linehan DC, et al. Mesh Reinforcement of Pancreatic Transection Decreases Incidence of Pancreatic Occlusion Failure for Left Pancreatectomy A Single-Blinded, Randomized Controlled Trial Ann Surg 2012; 255:10371042

18) Kraus TW, Mehrabi A, Schemmer $P$, Kashfi A, Berberat P, Büchler MW. Scientific Evidence for Application of Topical Hemostats, Tissue Glues, and Sealants in Hepatobiliary Surgery JACS 2005; 200: 418-27 
19) Montorsi M, Zerbi A, Bassi C, Capussotti L, Coppola R, Sacchi M, and the Italian TachoSil Study Group. Efficacy of an Absorbable Fibrin Sealant Patch (TachoSil) After Distal pancreatectomy A Multicenter, Randomized, Controlled Trial Ann Surg 2012;256: 853-60

20) Warshaw AL. Conservation of the spleen with distal pancreatectomy. Arch Surg 1988;123:550-3

21) Bassi $C$, Dervenis $C$, Butturini G, Fingerhut $A$, Yeo $C$, Izbicki J, et al. for the International Study Group on Pancreatic Fistula Definition. Postoperative pancreatic fistula: an international study group (ISGPF) definition. Surgery 2005; 138: 8-13

22) DeOliveira ML, Winter JM, Schafer M, Cunningham SS, Cameron JL, Yeo CJ, et al. Assessment of Complications After Pancreatic Surgery. A Novel Grading System Applied to 633 Patients Undergoing Pancreaticoduodenectomy Ann Surg 2006;244: 931-9

23) Champion HR, Fingerhut A, Escobar MA, Weiskopf RB. The Role of Data and Safety Monitoring in Acute Trauma Resuscitation Research JACS 2007; 204: 73-83

24) Moher D, Schulz KF, Altman DG, for the CONSORT Group. The CONSORT statement: revised recommendations for improving the quality of reports of parallel-group randomised trials Lancet 2001; 357: 1191-94 
25) Hopewell S, Loudon K, Clarke MJ, Oxman AD, Dickersin $\mathrm{K}$ Publication bias in clinical trials due to statistical significance or direction of trial results (Review) Cochrane Database of Systematic Reviews 2009, Issue 1. Art. No. : MR000006. DOI: 10.1002/14651858.MR000006.pub3 26) Dwan K, Altman DG, Arnaiz JA, Bloom J, Chan AW, Cronin E, Decullier E, Easterbrook PJ, Von Elm E, Gamble C, Ghersi D, loannidis JPA, Simes J, Williamson PR Systematic Review of the Empirical Evidence of Study Publication Bias and Outcome Reporting Bias PLoS ONE 2008 ; 3: e3081. doi:10.1371/journal.pone.0003081

27) Rozich N, Matos A, Gegios A, Winslow E. The Effect of Splenectomy on Complication Rates After Distal Pancreatectomy: a Meta-Analysis presented at the Society for Surgery of the Alimentary Tract Orlando May 17-21 2013 28) Adam JP; Jacquin A, Laurent $C$, Collet $D$, Masson B, Fernandez-Cruz L, et al. Laparoscopic Spleen-Preserving Distal Pancreatectomy Splenic Vessel Preservation Compared With the Warshaw Technique JAMA Surg 2013; 148: $246-52$

29) Carrere N, Abid S, Julio CH, Bloom E, Pradere B. Spleen-preserving Distal Pancreatectomy with Excision of Splenic Artery and Vein: A Case-matched Comparison with Conventional Distal Pancreatectomy with Splenectomy World J Surg 2007; 31: 375-82 
30) Rodriguez JR, Madanat MG, Healy BC, Thayer SP, Warshaw AL, et al. Distal pancreatectomy with splenic preservation revisited Surgery 2007; 141: 619-25

31) Jain G, Chakravartty $S$, Patel AG Spleen-preserving distal pancreatectomy with and without splenic vessel ligation: a systematic review HPB 2013, 15, 403-10

32) Venkat R, Edil BH, Schulick RD, Lidor AO, Makary MA, Wolfgang CL. Laparoscopic Distal Pancreatectomy Is Associated With Significantly Less Overall Morbidity Compared to the Open Technique A Systematic Review and Meta-Analysis Ann Surg 2012; 255:1048-59

33) Cho CS, Kooby DA, Schmidt CM, Nakeeb A, Bentrem DJ Merchant NB et al. Laparoscopic versus open left pancreatectomy: can preoperative factors indicate the safer technique? Ann Surg 2011;253:975-80

34) Butturini G, Partelli S, Crippa S, Malleo G, Rossini R, Casetti $L$, et al. Perioperative and long-term results after left pancreatectomy: a single-institution, non-randomized, comparative study between open and laparoscopic approach. Surg Endosc. 2011; 25: 2871-2878

35) Pannageon $V$, Pessaux $P$, Sauvanet $A$, Vullierme MP, Kianmanesh R, Belghiti J. et al. Pancreatic fistula after distal pancreatectomy: predictive risk factors and value of conservative treatment. Arch Surg 2006; 141: 1071-6 
36) Birth M, Figueras J, Bernardini S, Troen T, Günther K, Mirza $D$, et al. Collagen fleece-bound fibrin sealant is not associated with an increased risk of thromboembolic events or major bleeding after its use for haemostasis in surgery: a prospective multicentre surveillance study Patient Saf Surg 2009; 3: 13-21

37) Trinquart L, loannidis JPA, Chatellier G, Ravaud P. A test for reporting bias in trial networks: simulation and case studies. BMC Medical Research Methodology 2014 14:112 38) Claxton K, Cohen JT, Neumann PJ. When Is Evidence Sufficient? A framework for making use of all available information in medical decision making and for deciding whether more is needed. Health Affairs, 2005; 24: 93-101 


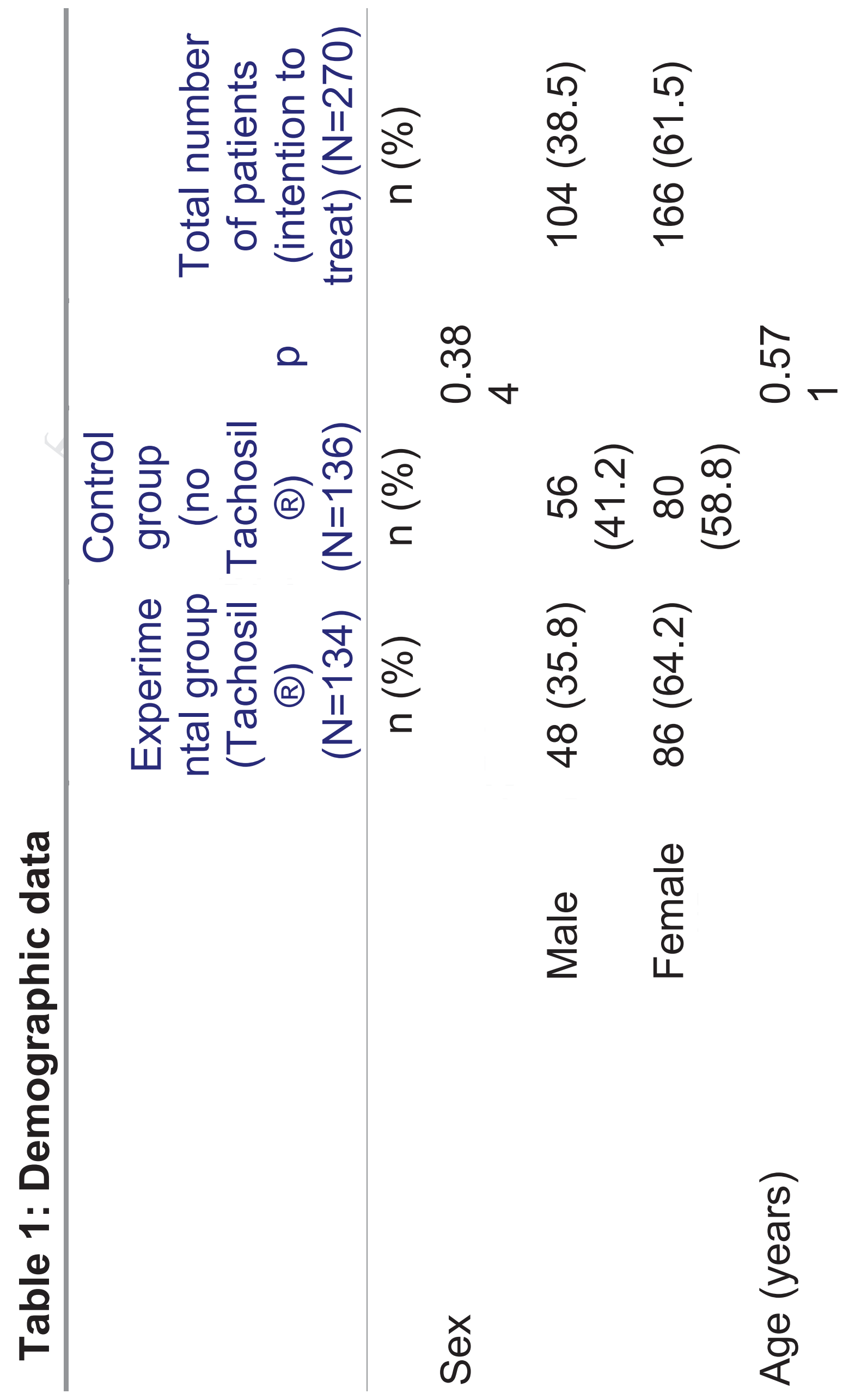




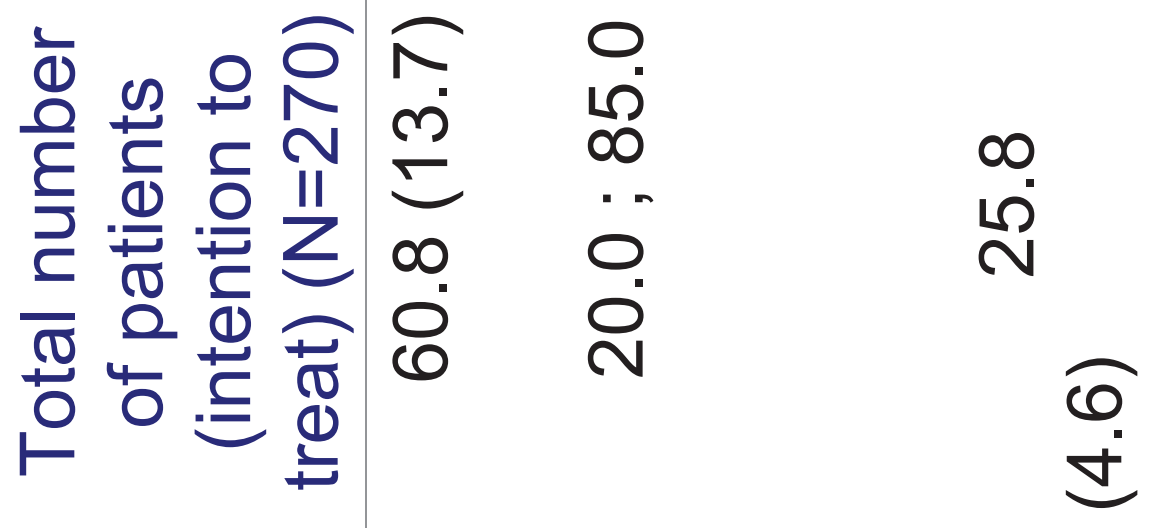

$$
\begin{aligned}
& \text { - } \stackrel{n}{0}
\end{aligned}
$$

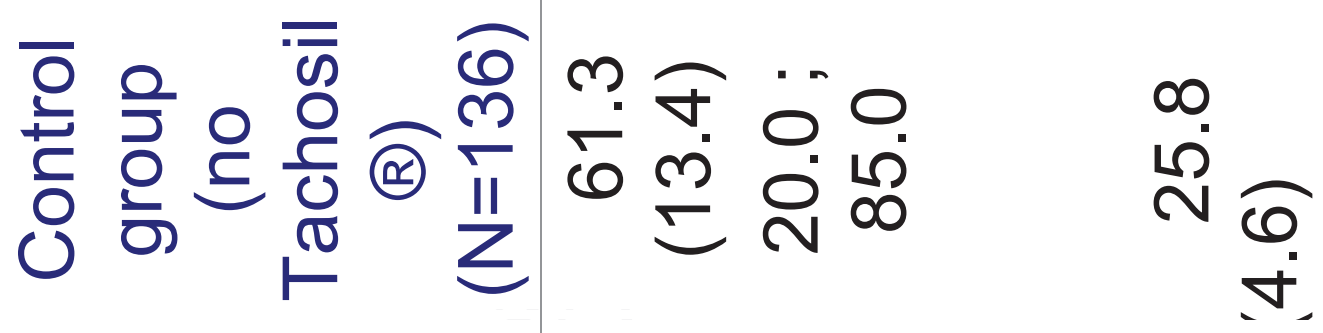

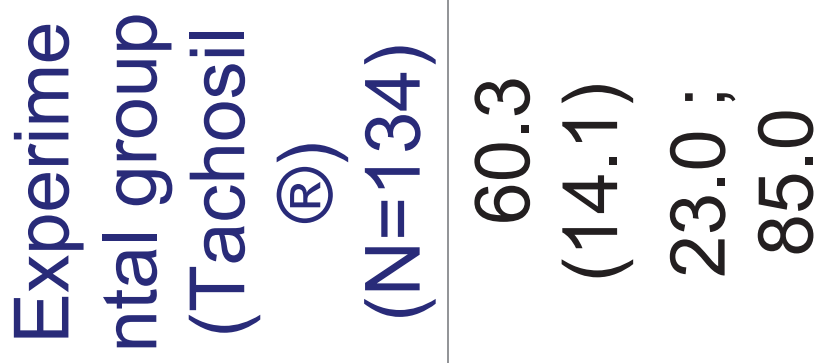

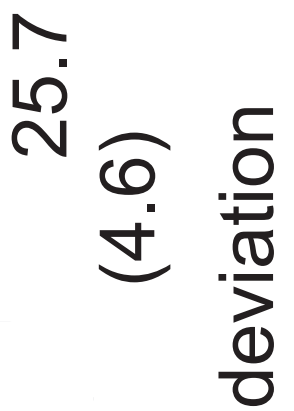

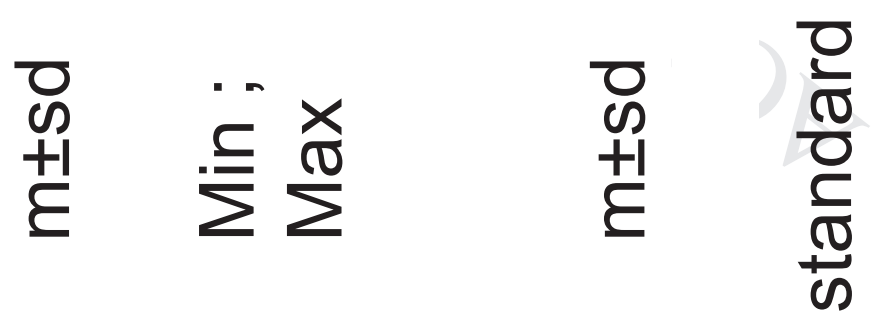

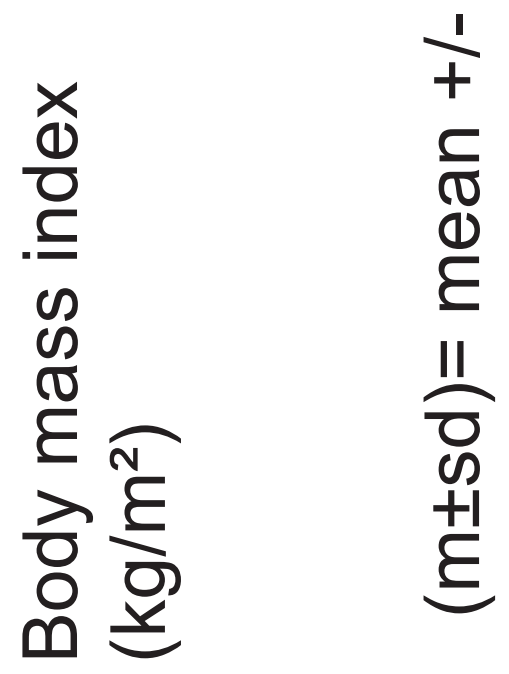




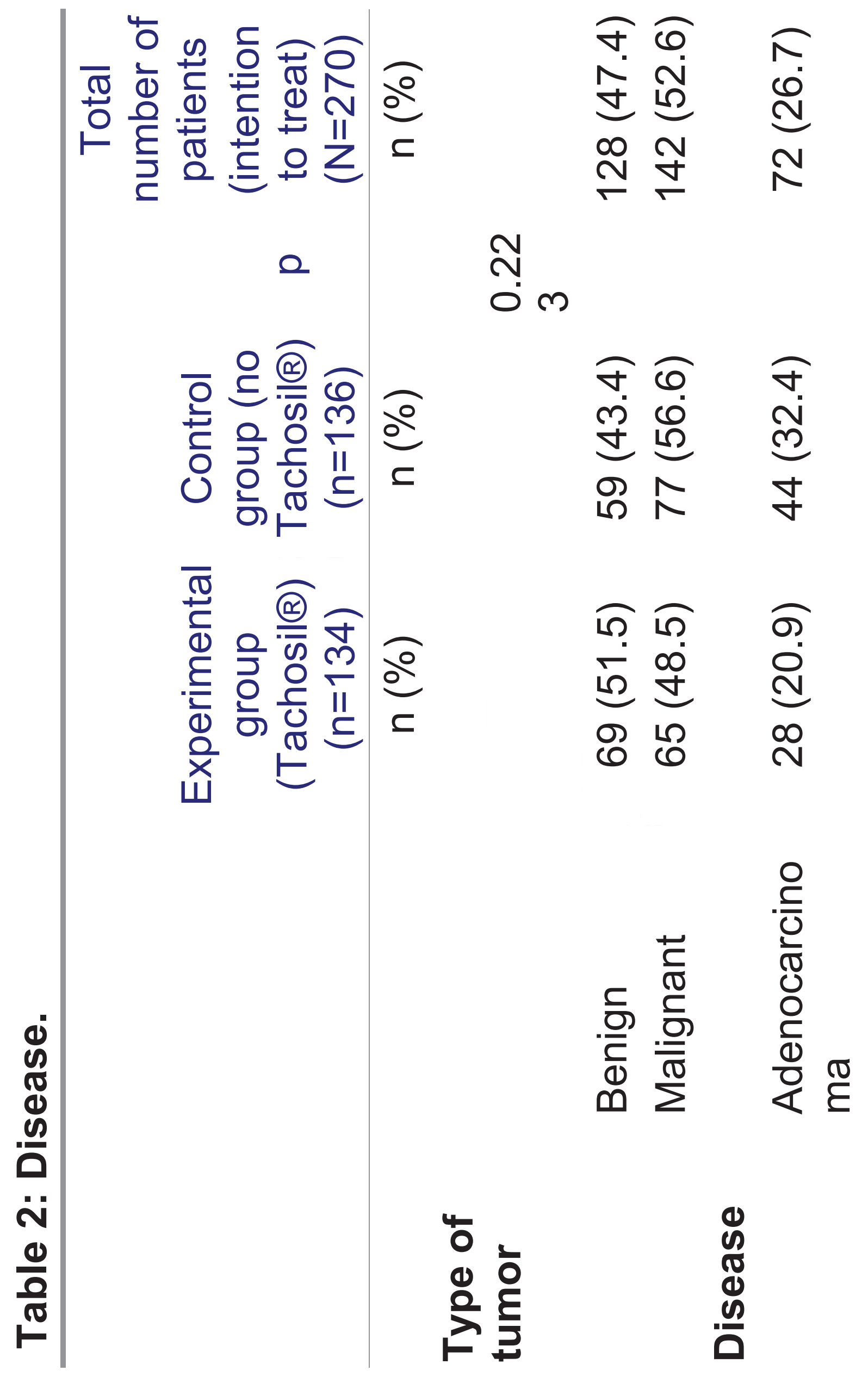




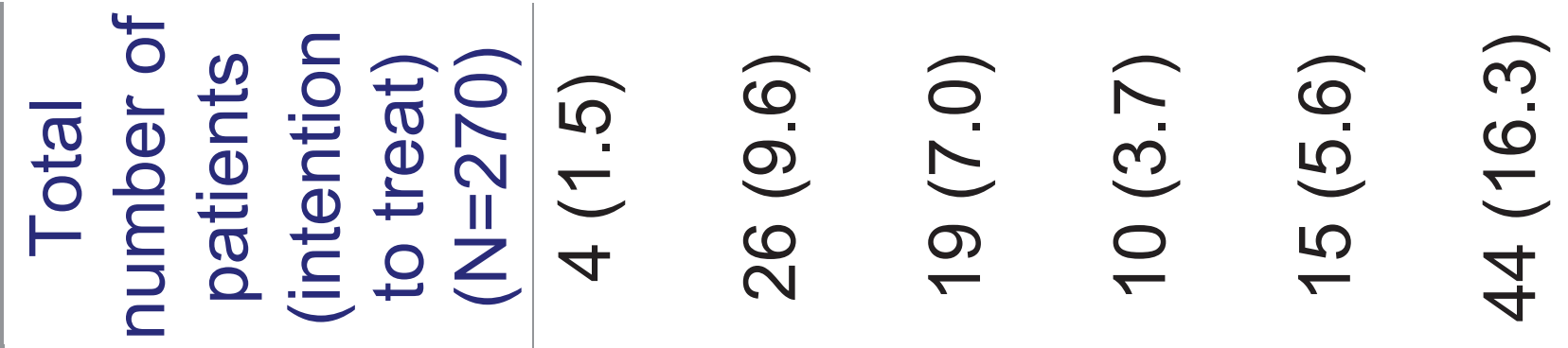

$$
\begin{aligned}
& \text { ○ }
\end{aligned}
$$

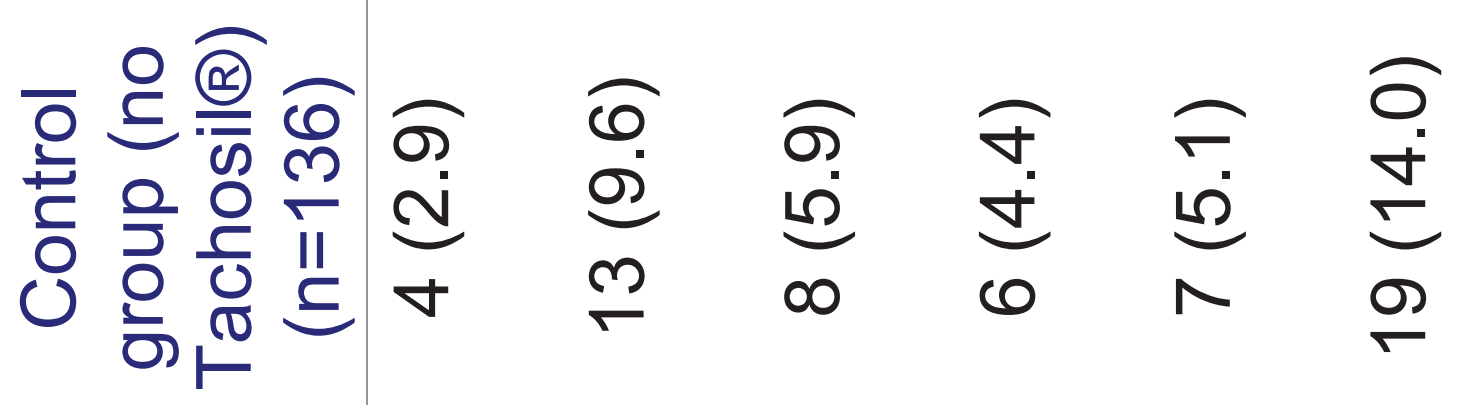

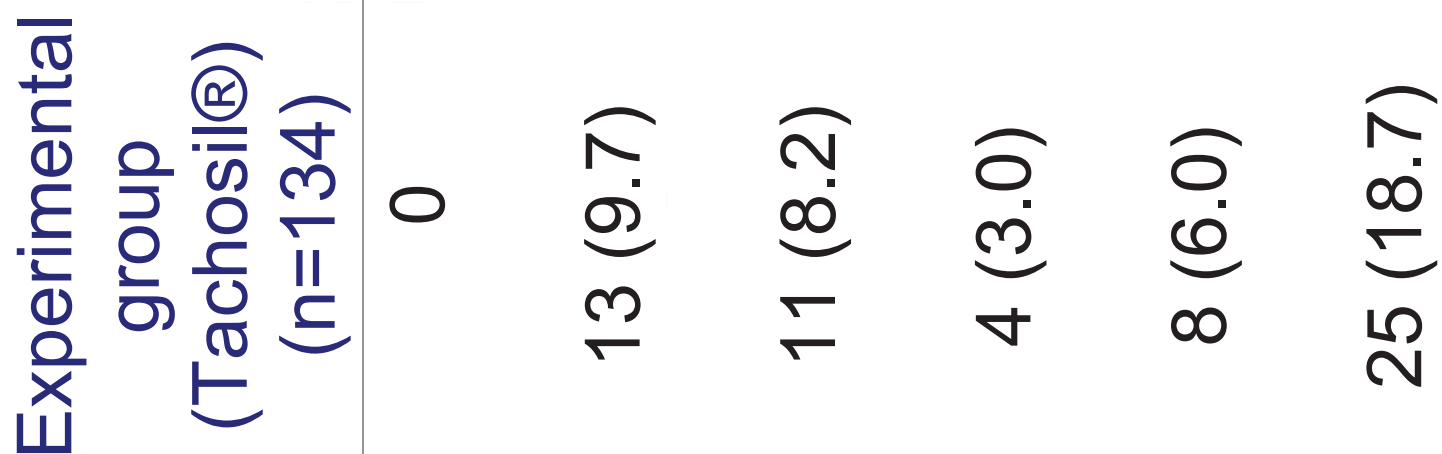

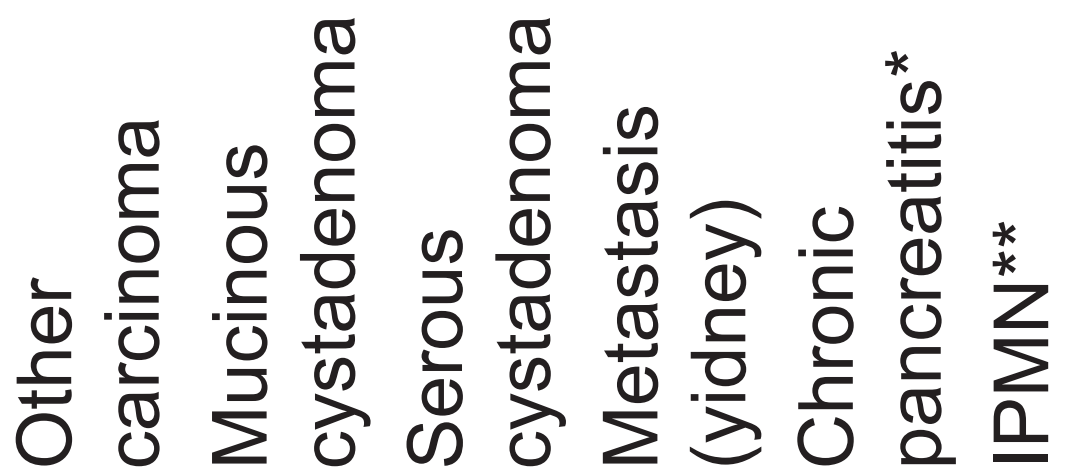




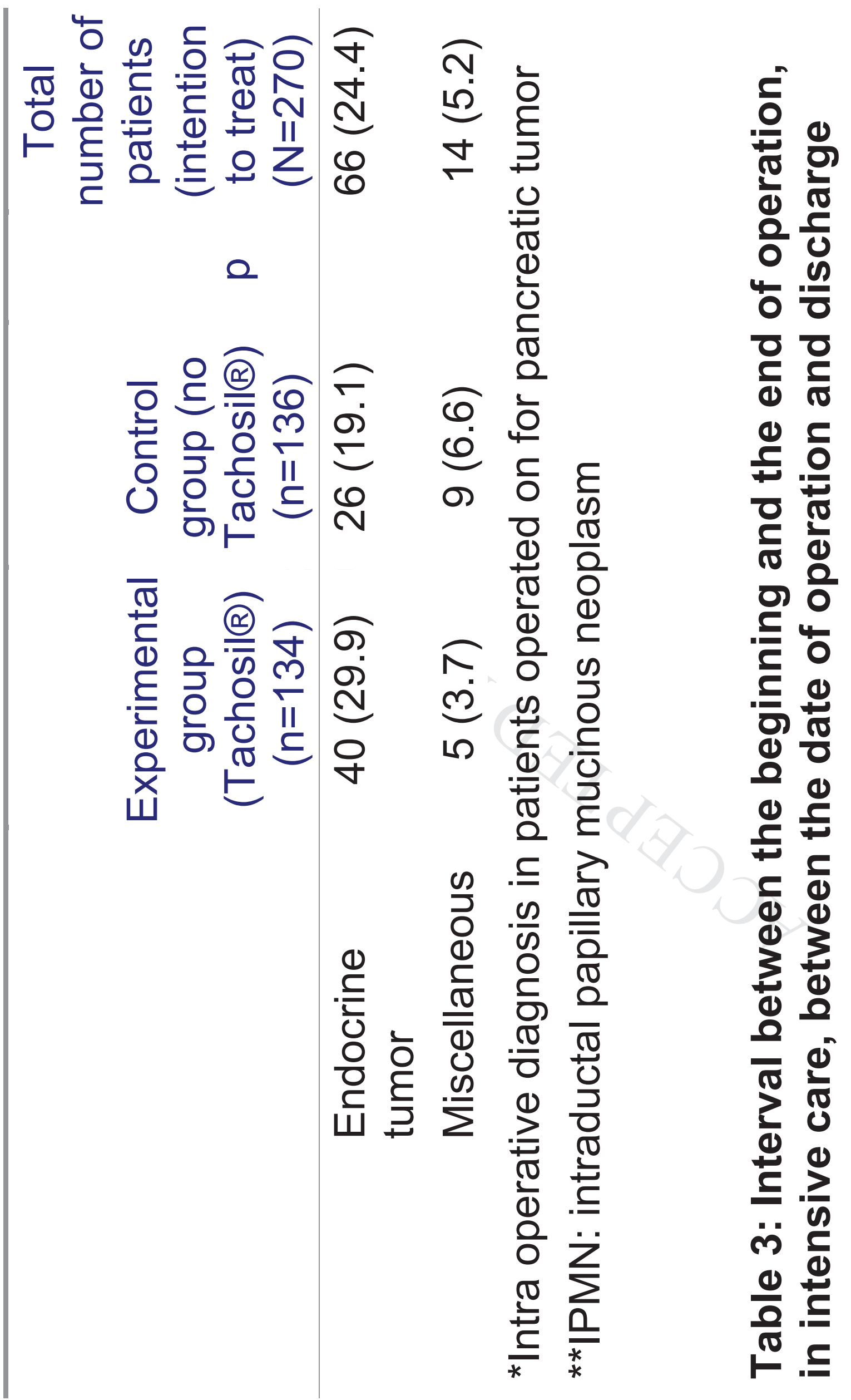




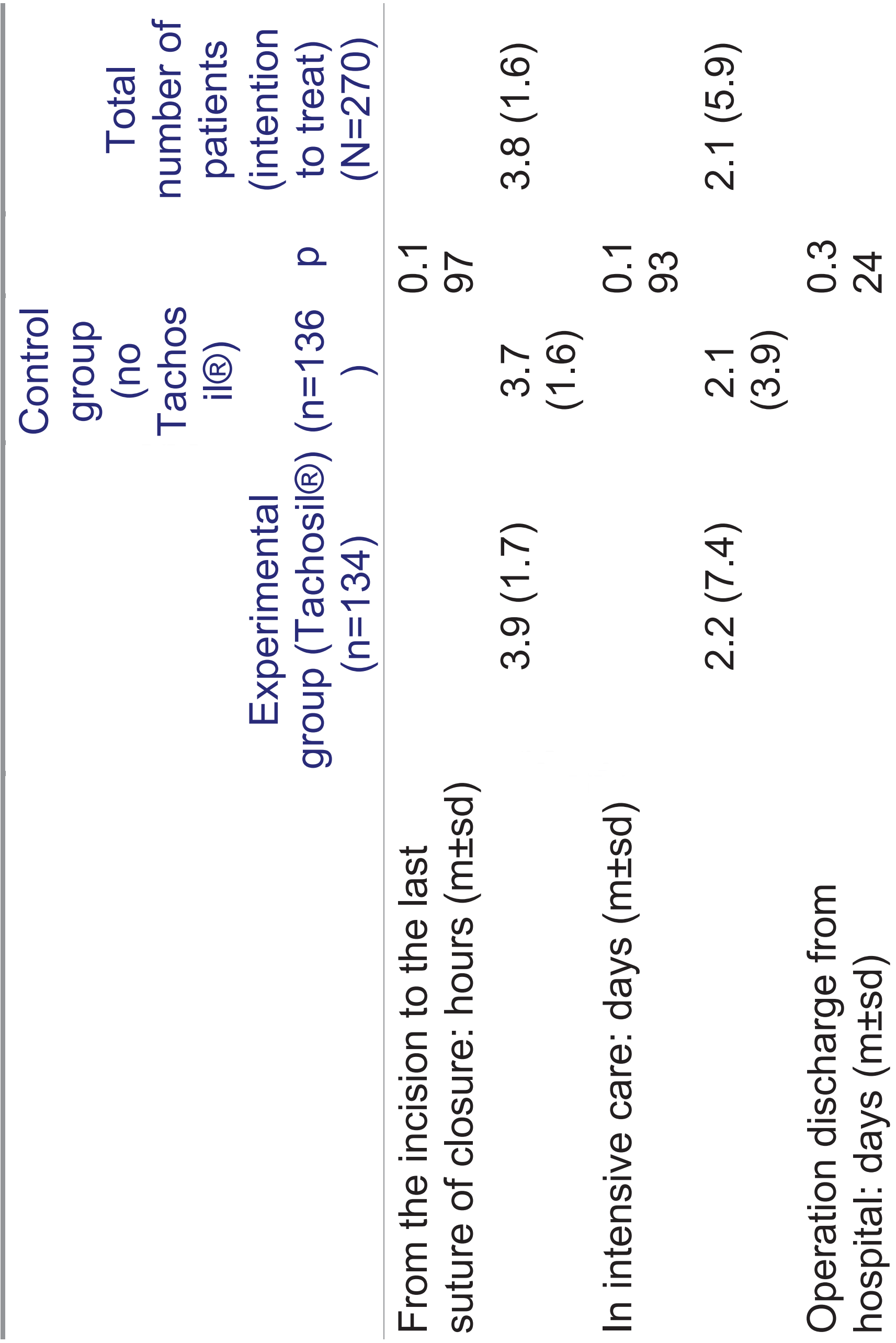




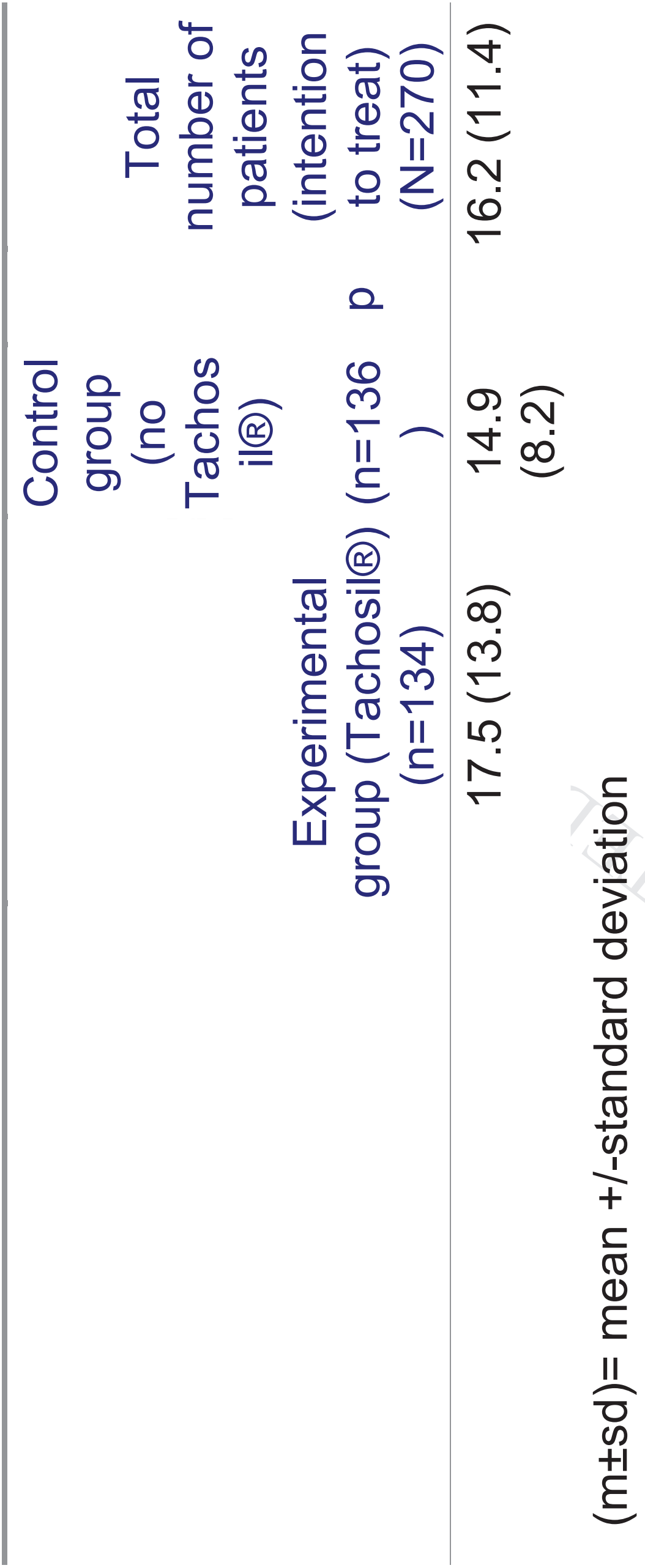




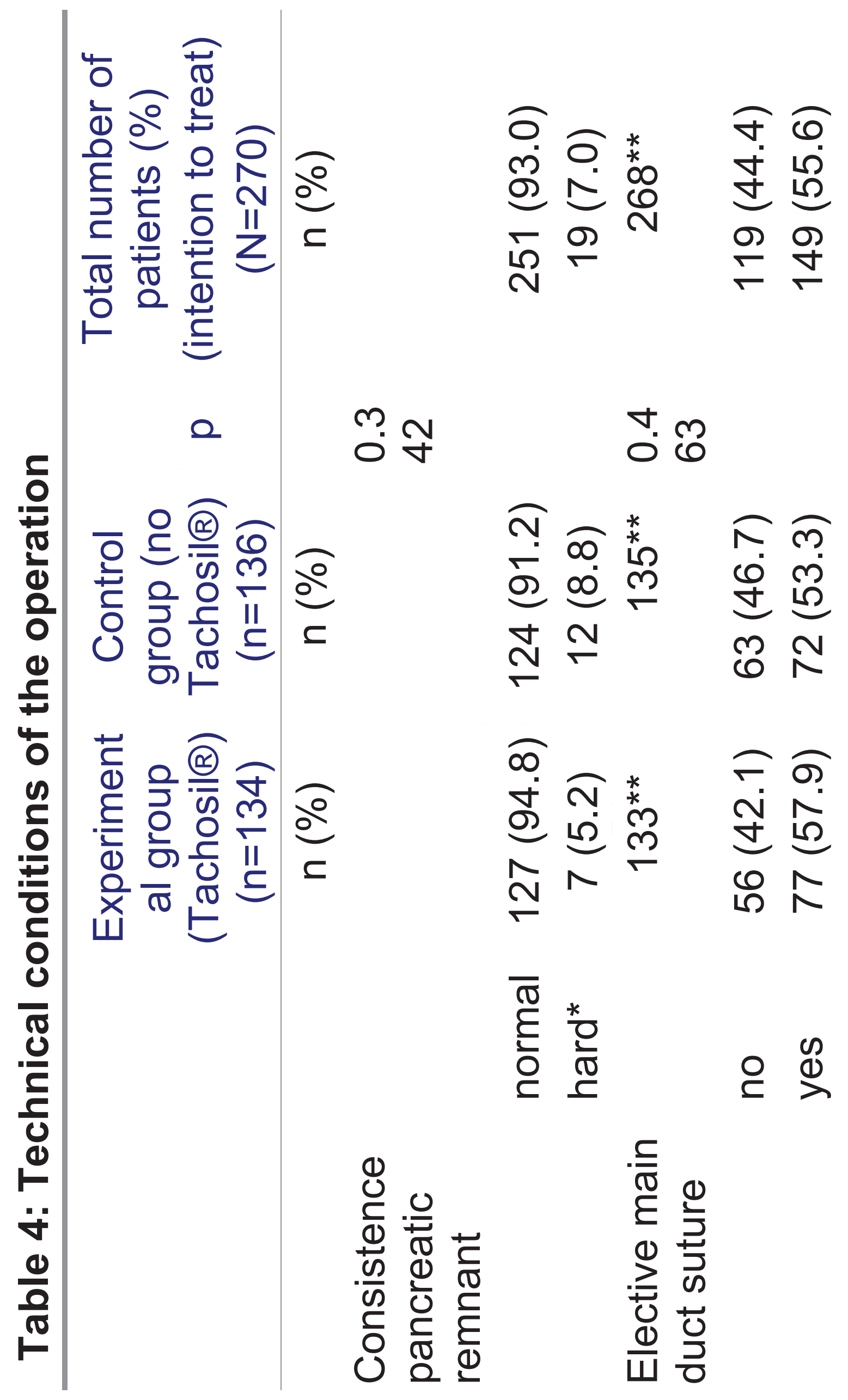




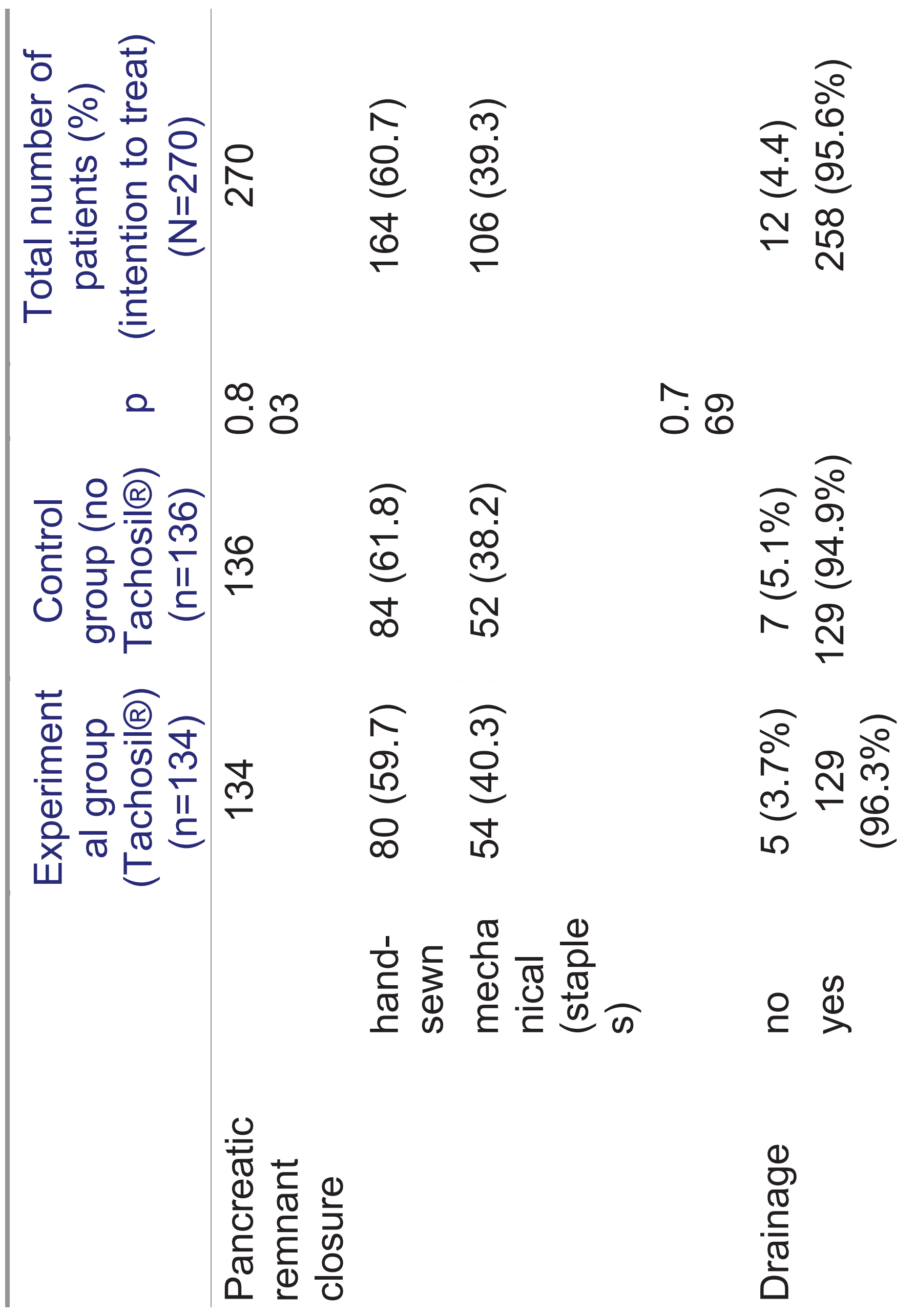




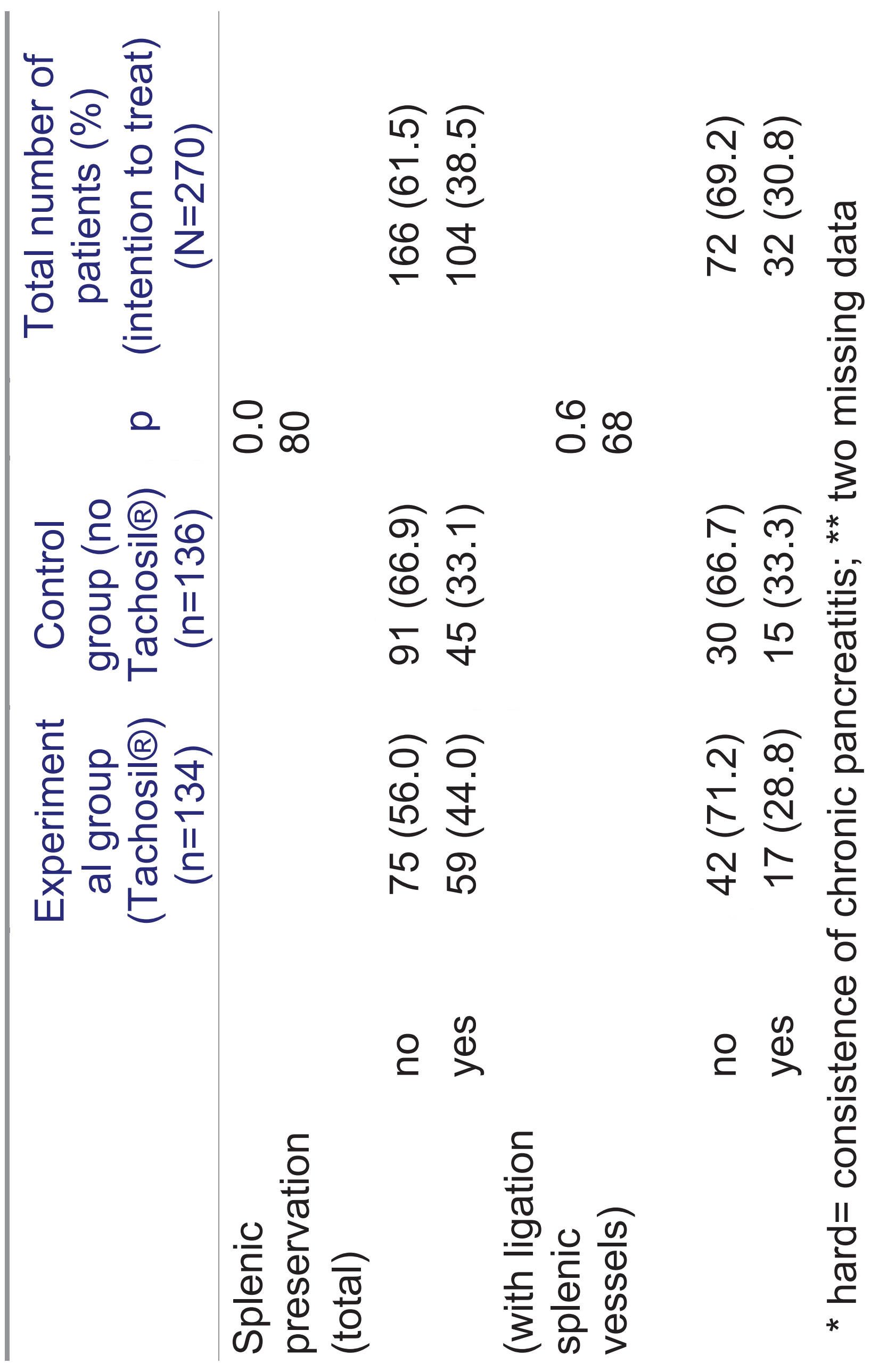




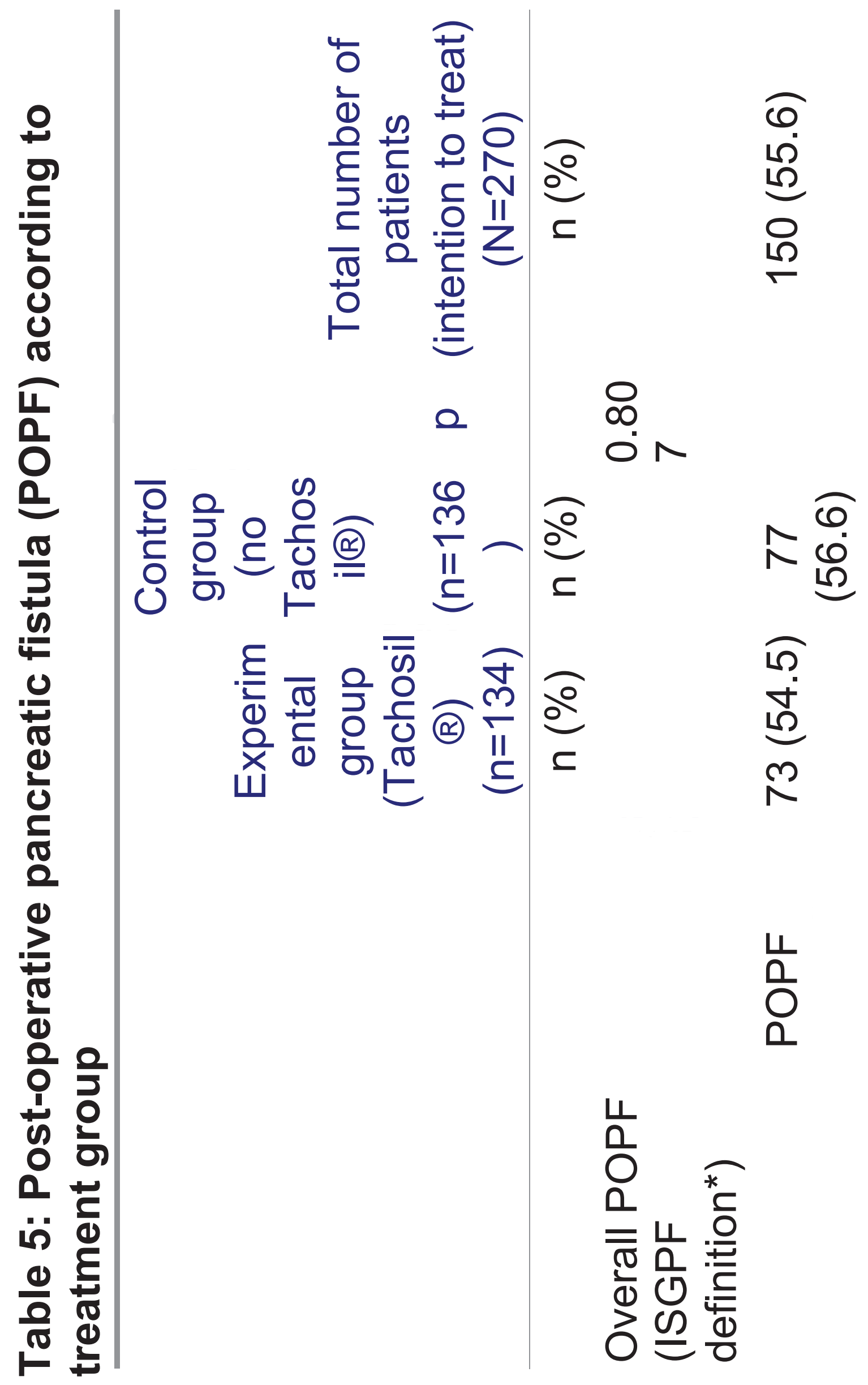




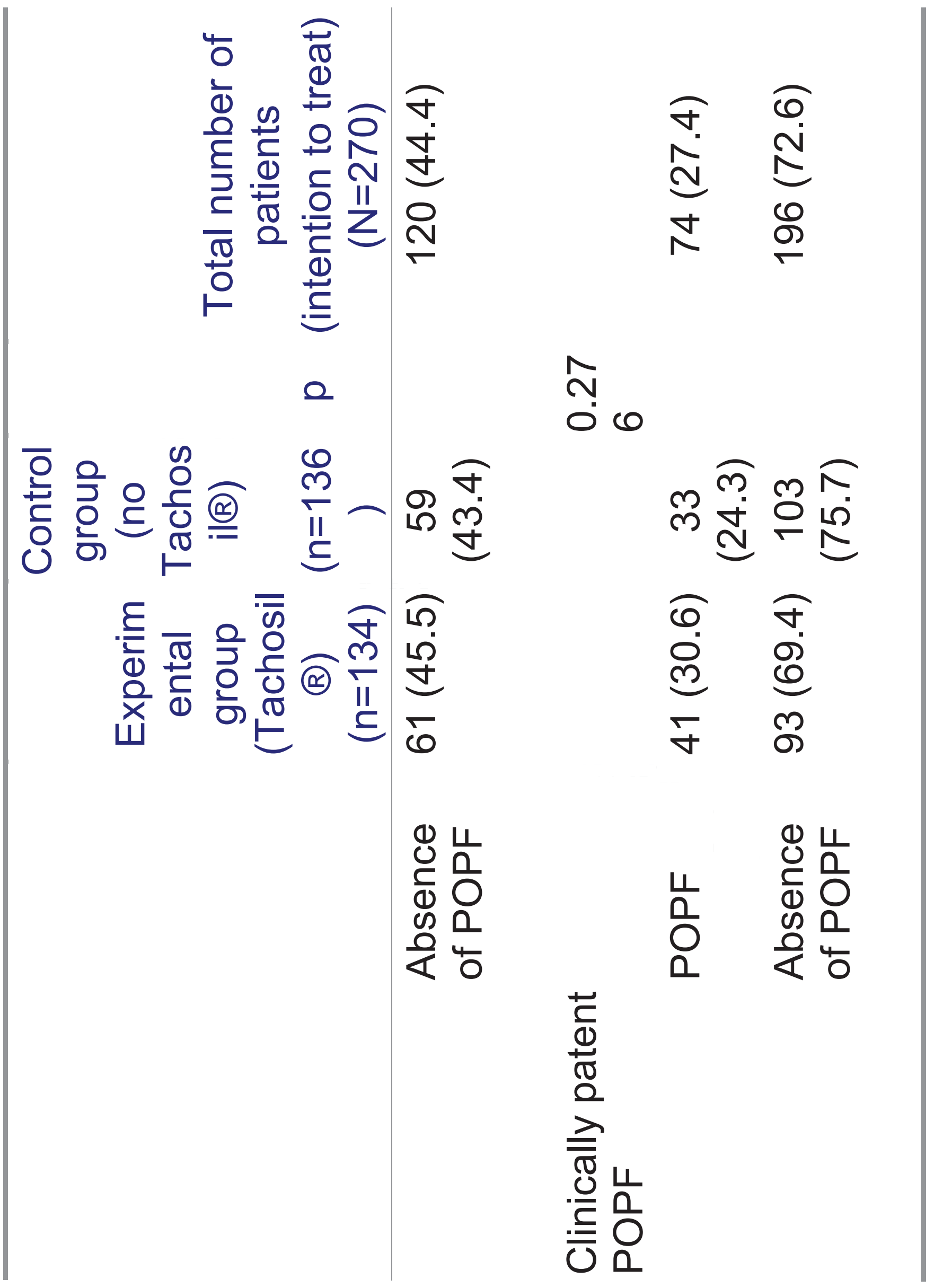


¿ั0

은

竞

$\overline{\widetilde{T}}$

음

$\stackrel{5}{\stackrel{5}{ \pm}}$

过

둥

음

동 중

응 흐

ํㅜㄴ $\frac{0}{5}$

잉 으

(1)

늠

(1)

( ) 


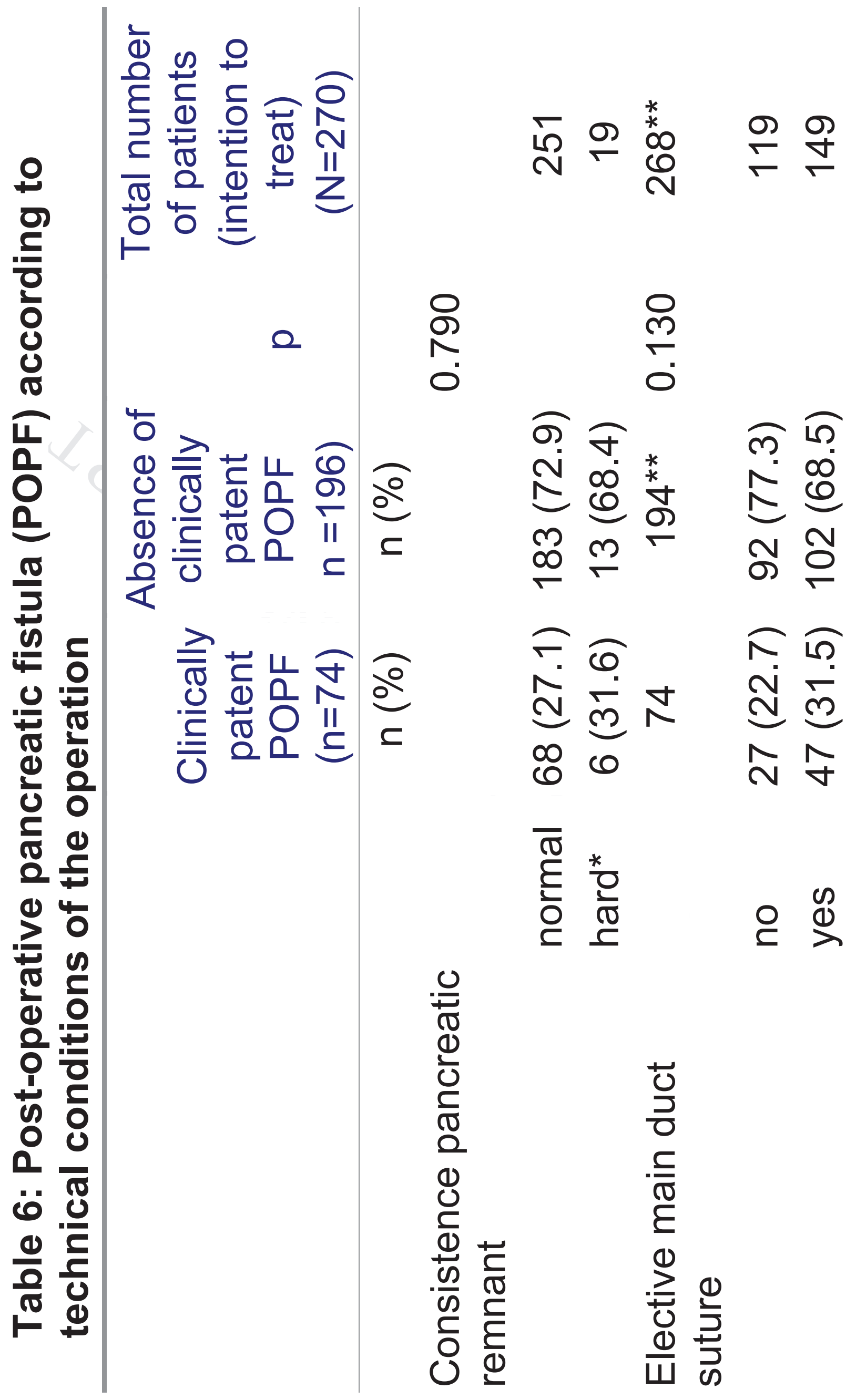




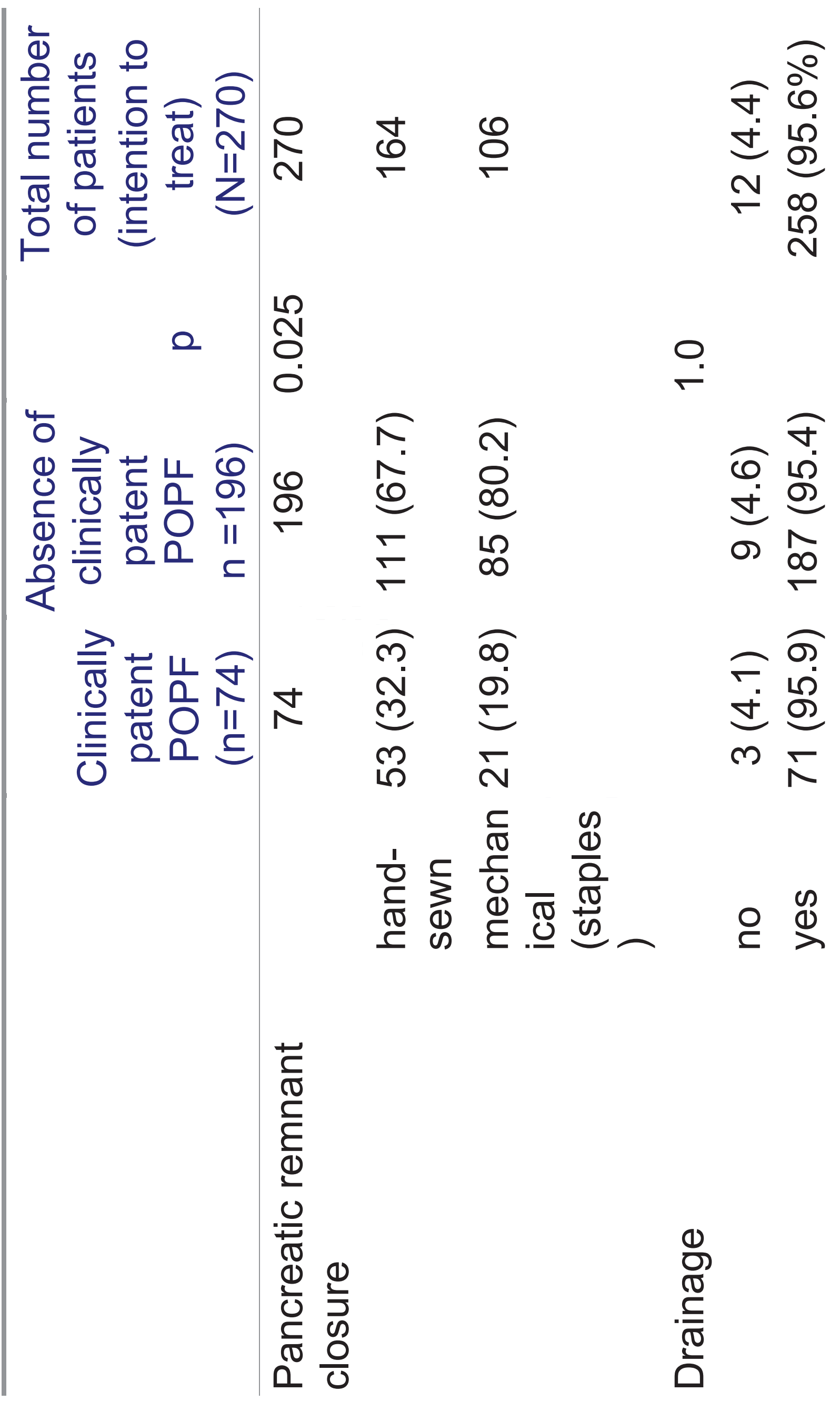




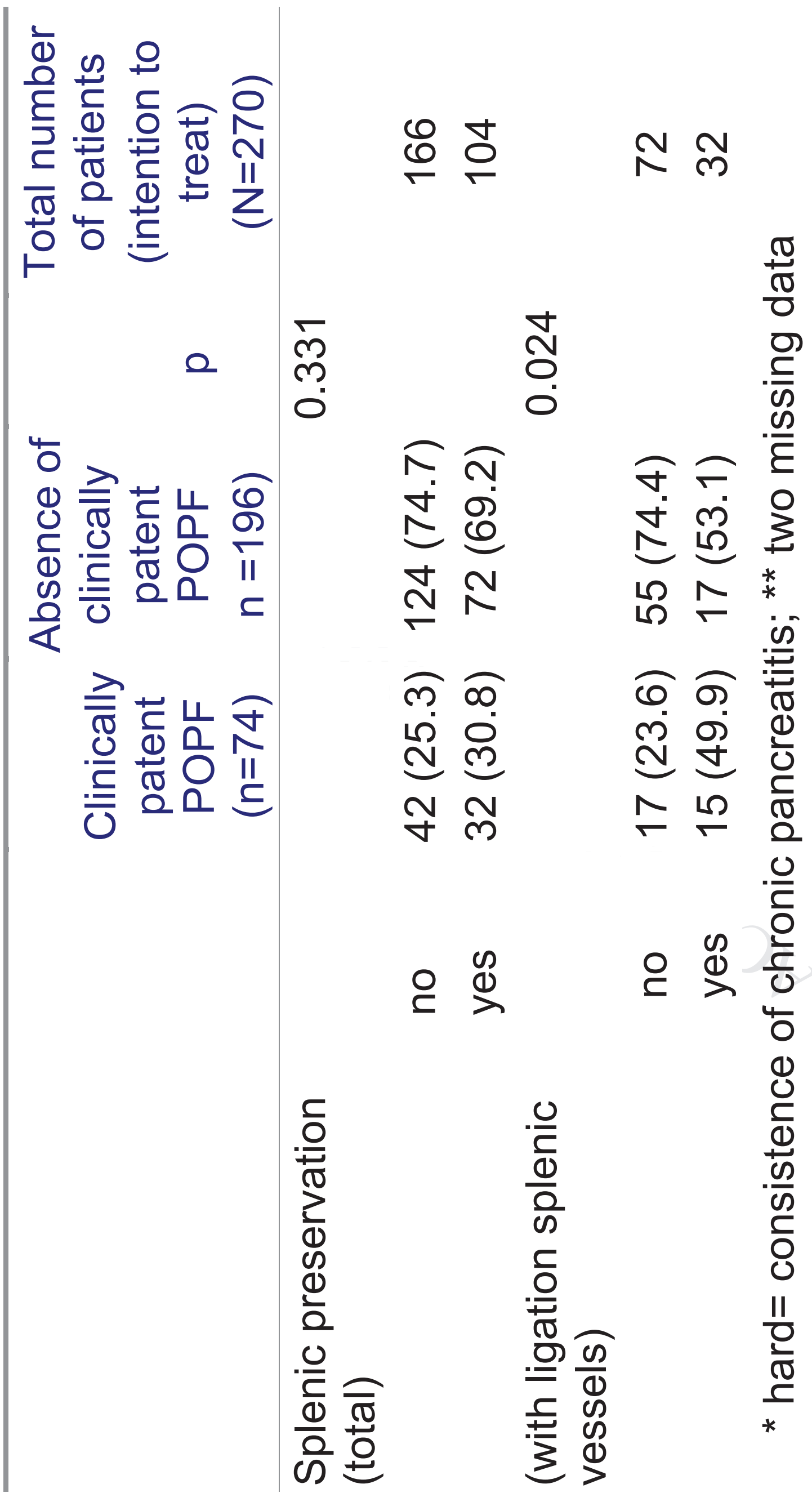




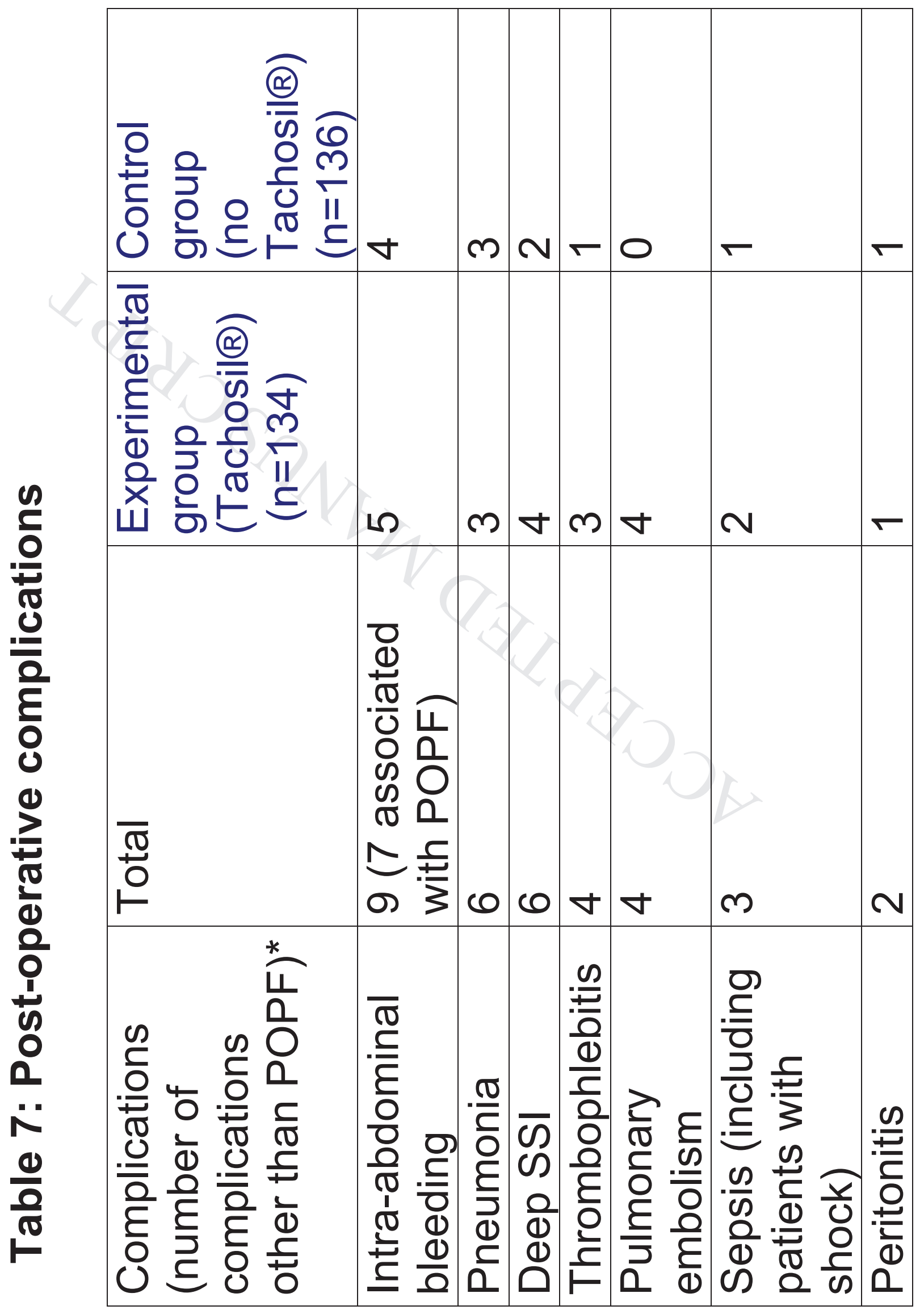




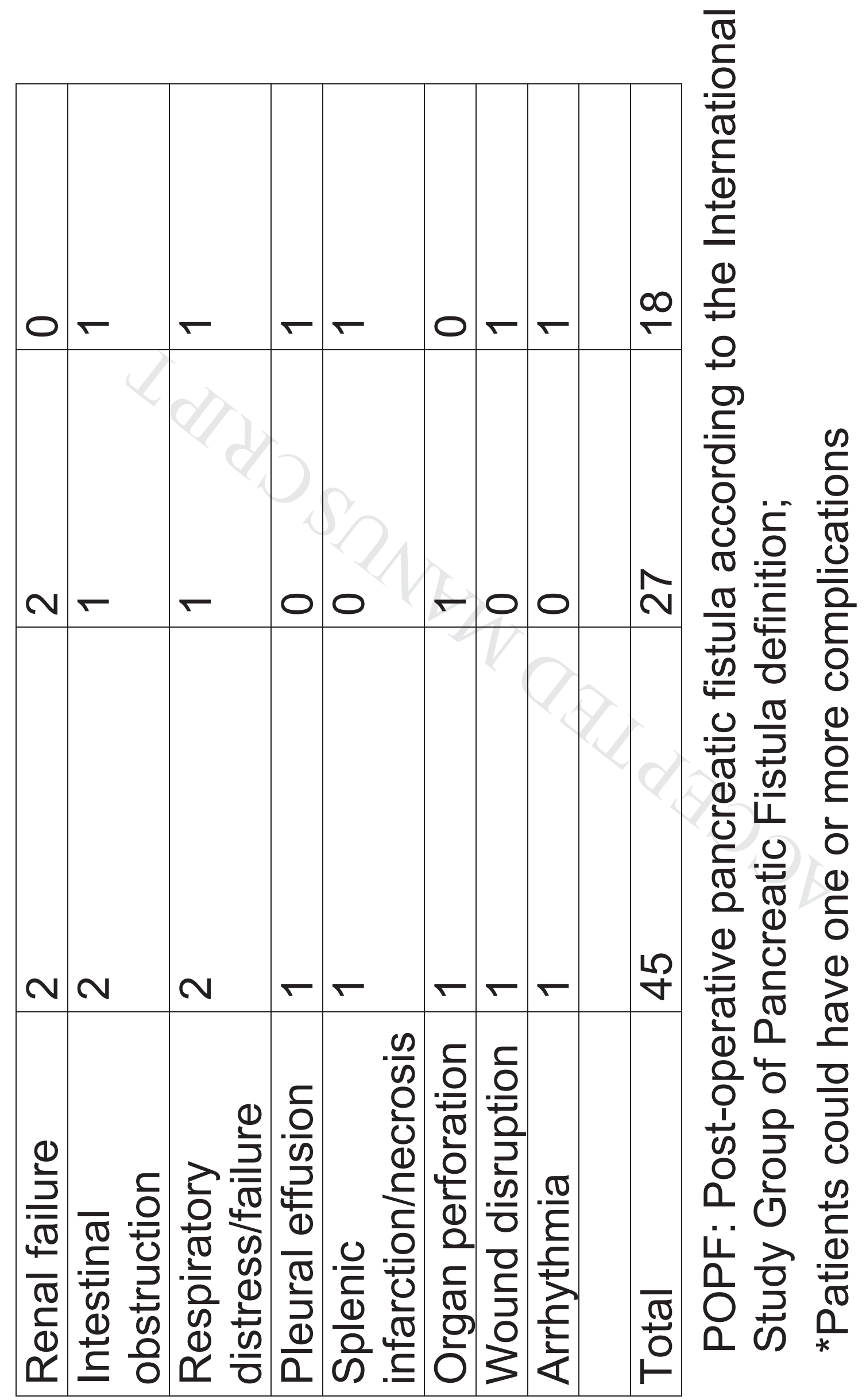


Figure 1: Flow Diagram of the randomization and population analysis

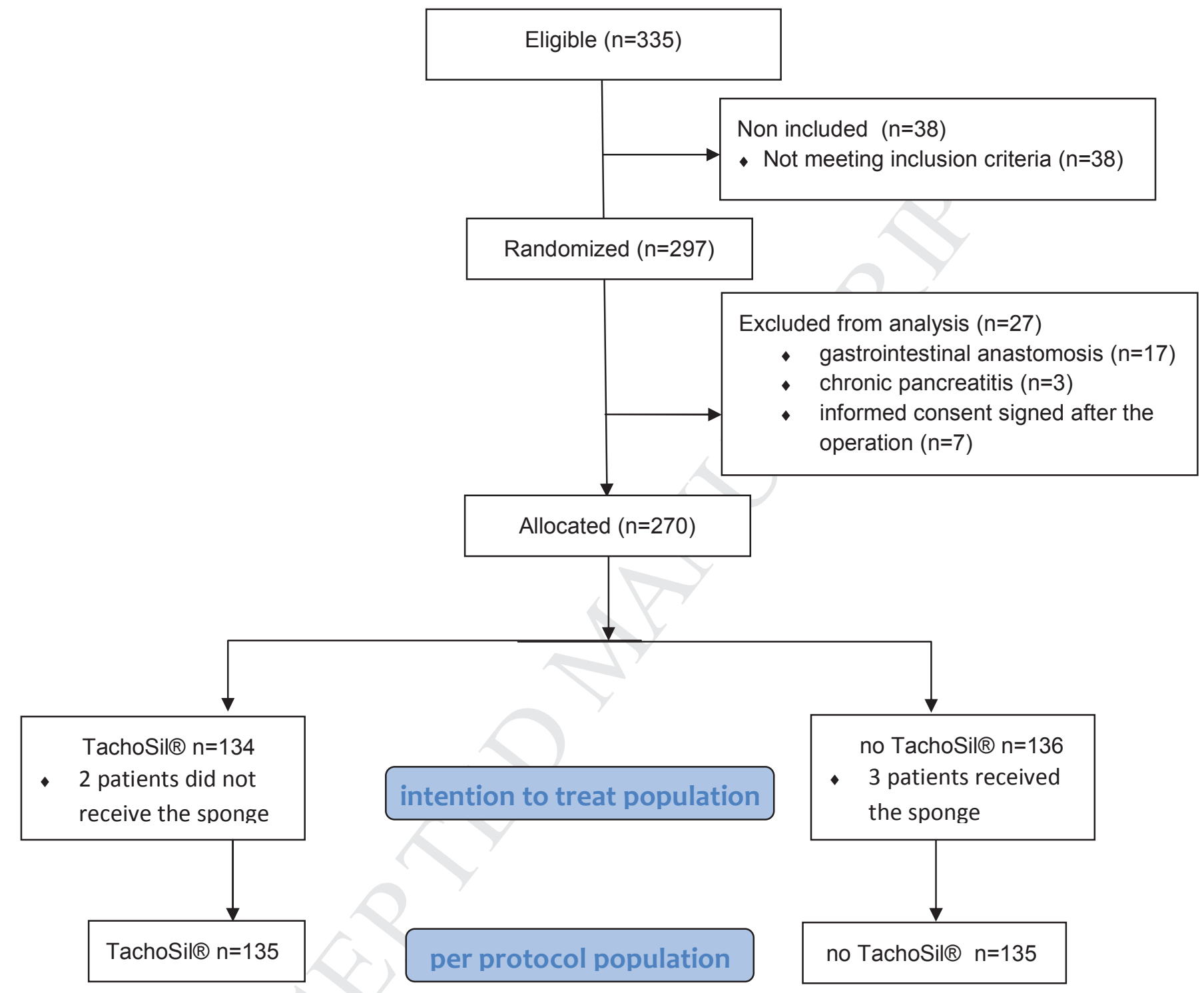

